\title{
La reforma constitucional y la nueva gobernanza económica de la Unión Europea
}

\author{
Josu de Miguel Bárcena \\ Universidad Autónoma de Barcelona
}

\begin{abstract}
Sumario: 1. Introducción.-2. La constitución económica y del proceso de integración europea. 2.1. La reforma del art. $135 \mathrm{CE}$ y la problemática conceptual sobre la constitución económica. 2.2. El sistema competencial de la Unión Europea en materia económica. 2.3. El Pacto de Estabilidad y Crecimiento en la constitución económica europea.-3. La recepción del principio de estabilidad presupuestaria en los Estados miembros, con especial referencia a España y Alemania. 3.1. Alemania, la estabilidad presupuestaria y el límite de endeudamiento: filosofía económica y constitucionalización. 3.2. La estabilidad presupuestaria en España antes de la reforma del art. 135 CE.-4. E1 nuevo art. $135 \mathrm{CE}$ a la luz de la nueva gobernanza económica europea. 4.1. Consideraciones generales en torno a la reforma. 4.2. El principio de estabilidad dentro de un presupuesto europeizado. 4.3. Disciplina fiscal y control del endeudamiento: del art. 135 $\mathrm{CE}$ al derecho comunitario. 4.4. Vigilancia y sanción en el marco del principio de estabilidad presupuestaria: el «nuevo» procedimiento de déficit excesivo.-5. Conclusiones.
\end{abstract}

\section{INTRODUCCIÓN}

De todos es sabido que en Europa, a diferencia de Estados Unidos, hasta que el constitucionalismo democrático no se afianzó después de la II Guerra Mundial, el instituto de la reforma constitucional no se convirtió en una verdadera garantía jurídica. Sin embargo, se ha destacado que precisamente por ello, la reforma deja de ser el instrumento fundamental para adecuar el texto constitucional a la mutable realidad social y política sobre la que pretende operar, convirtiéndose, por el contrario, en la garantía excepcional, que se yuxtapone a la garantía normal, la justicia constitucional, la cual, a través de la interpretación de la Constitución, es la que efectúa básicamente la operación de adecuar la norma constitucional a la realidad. La reforma de la Constitución queda en cierta medida como un recurso de emergencia, al que hay que acudir cuando no es posible solucionar el problema de que se trate mediante la interpretación constitucional ${ }^{1}$.

La razón para ello hay que encontrarla en la importancia que tiene el mantener estables las garantías jurídicas del pacto político que subyace a toda Constitución democrática. La reforma constitucional entra así en el escenario político cuando la excepcionalidad de la situación lo requiere, si bien

1 Pérez Royo, J., «La reforma de la Constitución», Revista de Derecho Político, núm. 22, 1986, p. 59. 
es cierto que la experiencia alemana e italiana a este respecto, demuestra que puede hacerse un uso razonable y normalizado de las reformas constitucionales como instrumento de mejora de los ámbitos que tradicionalmente regula la Norma Fundamental2.

La experiencia de España con la reforma constitucional no ha sido especialmente fructífera. Históricamente, porque nuestro país no ha construido una verdadera cultura constitucional más allá del partidismo o el concepto meramente político (en el peor sentido de la palabra) de Constitución ${ }^{3}$. No es, pues, hasta 1978, cuando después de una difícil pero exitosa transición política desde la dictadura franquista, cuando se supera la tradición partidista en torno a la Constitución en España (en adelante CE). Ello explica que en sus más de tres décadas de existencia, el instituto de la reforma constitucional haya sido utilizado quizá con excesiva cautela. Reservas que sin duda se refuerzan por el miedo a que el planteamiento de cualquier reforma de la Constitución, por técnica y funcional que sea, pueda llevar a un cuestionamiento del sujeto que la legitima y la forma política que instituye ${ }^{4}$.

Ha sido, sin embargo, en el ámbito de la integración del Estado español en una organización supranacional, esto es, la Unión Europea (en adelante UE), donde nuestra Constitución ha puesto en marcha el instituto de la reforma en dos ocasiones. La primera, como consecuencia de la ratificación del Tratado de Maastricht, en agosto de 1992, después del Dictamen del Tribunal Constitucional, cuando se introdujo la posibilidad de que los ciudadanos comunitarios pudiesen ser elegibles en las elecciones municipales, mediante la reforma del art. 13.2 $\mathrm{CE}^{5}$. La segunda, en agosto de 2011 (por lo tanto, también en pleno periodo estival), con motivo de la introducción del principio de estabilidad presupuestaria establecido en el Tratado de Funcionamiento de la Unión Europea (en adelante TFUE) en el art. $135 \mathrm{CE}$, en un contexto de grave crisis de confianza de la economía española y comunitaria, y en respuesta a los desafíos planteados por los problemas de nuestra Hacienda para colocar la deuda soberana que provisiona de recursos financieros a España.

2 El aspecto decisivo en la consideración de una eventual reforma constitucional ha sido históricamente el factor «tiempo»; al respecto, ver CABO MARTín, C., La Reforma constitucional en la perspectiva de las Fuentes del Derecho, Trotta, Madrid, 2003, p. 15 y ss. Sin embargo, la globalización impone tener en cuenta el factor «espacio»; ZüRN, M., «Democratic Governance Beyond the Nation-State: The EU and Other International Institutions», European Journal of International Relations, Vol. 6, núm. 2, 2000.

${ }^{3}$ Con los matices necesarios, Varela Suanzes, J., Politica y Constitución en España (1808-1978), Centro de Estudios Constitucionales, Madrid, 2008; y Torres Del Moral, A., Constitucionalismo histórico español, ATOMO, Madrid, 1986.

${ }^{4}$ Hablamos, obviamente, de las ya seculares tensiones nacionalistas. Al respecto, ver Ruipérez Alamillo, J., Entre el federalismo y el confederantismo. Dificultades y problemas para la formulación de una teoría constitucional del Estado de las autonomías, Biblioteca Nueva, Madrid, 2010.

${ }^{5}$ Aragón, M., «La Constitución española y el Tratado de la Unión Europea: la reforma constitucional», Revista Española de Derecho Constitucional, núm. 42, 1994. 
El objetivo central de este trabajo no será cuestionarnos sobre la oportunidad de la última reforma; tampoco si el proceso político y el procedimiento parlamentario han sido correctos desde la perspectiva del consenso, la transparencia o la participación democrática. Se ha señalado, en este sentido, que la reforma de agosto de 2011 entraría dentro de un «derecho constitucional simbólico», pues su eficacia jurídica es limitada y la remisión a la ley orgánica del art. $135 \mathrm{CE}$ constituye una vía de escape lo suficientemente flexible como para eludir los compromisos alcanzados por nuestro Estado en el marco del derecho originario y derivado de la Unión Europea. Conviene, desde este punto de vista, considerar la reforma no solo desde los condicionamientos planteados en clave interna, sino interpretarla teniendo en cuenta las exigencias, cada vez más profusas e intensas, del derecho comunitario sobre la materia.

Pues bien, en nuestra opinión, la reforma del art. 135 CE y el principio de estabilidad presupuestaria que incorpora tiene una mayor importancia de la que inicialmente se le ha dado. La razón hay que encontrarla en el modelo de constitución económica que pergeñan los Tratados comunitarios y el derecho derivado comunitario, ambos en constante reforma desde Maastricht. Solo desde una consideración aislada de la Constitución, al margen de la potencia integradora ${ }^{6}$ que en los últimos años está mostrando el ordenamiento jurídico comunitario (caracterizado como multinivel o pluralista), puede afirmarse que el principio de estabilidad presupuestaria no va a tener consecuencias jurídicas y políticas en el modelo de constitución económica de la Norma Fundamental española. Cosa distinta es que ello afecte al despliegue del Estado del bienestar en nuestro país, pues ello dependerá, como hasta ahora, de la capacidad de reinvención que el modelo de crecimiento económico español y europeo tenga en los próximos años.

Para afrontar nuestro análisis dividiremos nuestro trabajo en cuatro partes. En primer lugar abordaremos, atendiendo a la obligada renovación doctrinal a la que obligan los acontecimientos, el concepto de constitución económica y su evolución desde la perspectiva estatal y supranacional. Nuestra tesis es, a este respecto, que la disposición institucional y competencial del ordenamiento comunitario implica una exposición importante de los elementos constitutivos de la constitución económica nacional, lo que ha permitido interpretar la relación entre ambos sistemas en términos contextuales y dinámicos, al menos hasta que ha estallado la crisis. En segundo lugar, analizaremos el Pacto de Estabilidad y Crecimiento (origen de la reciente reforma constitucional) desde el punto de vista de los instrumentos del gobierno de la economía (o gobernanza) que han ido construyéndose en las dos últimas décadas en el proceso de integración europea. En la tercera parte, aludiremos a la experiencia en lo referente al momento normativo concreto en el que los

${ }^{6}$ López Castillo, A., Constitución e integración, Centro de Estudios Constitucionales, Madrid, 1996. 
Estados miembros han de aplicar los principios de estabilidad presupuestaria prescritos en la Unión Europea. Para ello, realizaremos un breve análisis tanto de la experiencia comparada, especialmente del caso alemán, como del desarrollo que en nuestro país han tenido tales principios desde que se incorporara al proyecto de moneda única. En último lugar, haremos un juicio abstracto sobre la posible eficacia de la reforma del art. $135 \mathrm{CE}$, teniendo en cuenta los parámetros de relación entre la Constitución nacional y el derecho comunitario, pero sobre todo los extraordinarios desarrollos que en los últimos tiempos está experimentando la gobernanza económica europea, en el marco de lo que bien puede denominarse como incipiente derecho constitucional de la crisis?.

\section{LA CONSTITUCIÓN ECONÓMICA Y DEL PROCESO DE INTE- GRACIÓN EUROPEA}

La reforma del art. 135 CE supone, antes de nada, la reforma de un elemento de la constitución económica española que ha resultado intranscendente hasta que como consecuencia de la crisis, las instituciones comunitarias y los Estados miembros con mayor peso en la Unión Europea han conminado a los Gobiernos nacionales a cumplir con los requisitos del Pacto de Estabilidad y Crecimiento, como condición para poner en marcha las diferentes formas de rescate en el marco de los problemas con la deuda soberana de países como Grecia, Portugal o España. Puede decirse, en este sentido, que como la mayor parte de las normas incluidas en el Título VII de la CE, el art. 135 ha sido patrimonio de expertos en derecho financiero y hacienda pública ${ }^{8}$.

Ahora bien, resulta innegable, igualmente, que la desatención por los aspectos hacendísticos y financieros de nuestra Constitución, proviene de la falta de interés que en los últimos años ha concitado el concepto de constitución económica. Dejando al margen los estudios primigenios con un sentido verdaderamente constitucional ${ }^{9}$, podría decirse que el interés por las cláusulas económicas que contiene la CE 1978, ha ido decreciendo, a la par que España se integraba precisamente en un espacio jurídico, el europeo, cuyo fun-

7 En un sentido más general, EmBID Irujo, A., El derecho de la crisis económica, Prensas Universitarias de Zaragoza, Zaragoza, 2009.

${ }^{8} \mathrm{Al}$ respecto, ver HuCHA CELADOR, F. de la, «El principio de inclusión presupuestaria automática: acotaciones del artículo 135.2 de la Constitución», Revista española de derecho financiero, núm. 63, 1989; o GonzÁlez SÁnchez, M., «Principios constitucionales que informan la deuda pública» en VV.AA., Gobierno y administración en la Constitución, Vol. 1, Instituto de Estudios Fiscales, Madrid, 1988, pp. 819-849.

9 Ver, en este sentido, los estudios comprehensivos de Juan Asenjo, O. de, La Constitución económica española, Centro de Estudios Constitucionales, Madrid, 1984; BAssols Coma, M., Constitución y sistema económico, Tecnos, Madrid, 1988; y el análisis parcial de García Pelayo, M., "Consideraciones sobre las cláusulas económicas en la Constitución», en Ramírez, M. (dir.), Estudios sobre la Constitución española de 1978, Pórtico, Zaragoza, 1979. 
damento último se encuentra precisamente en la construcción de un mercado único a través de una regulación sustantiva que pone esencialmente atención en el derecho público económico ${ }^{10}$. Y así, la constitución económica ha ido desapareciendo no solo de los manuales, sino correlativa y lógicamente, de los programas de las asignaturas de derecho constitucional de las Universidades españolas. No interesa, desde luego, alargarse más sobre esta cuestión.

Pero sin embargo, por sí solo, el hecho de la reforma constitucional, tan extraña a nuestra tradición jurídico-política, es motivo suficiente para volver a hablar de la constitución económica en el marco de la reforma del art. $135 \mathrm{CE}$. Sin embargo, bien puede afirmarse que en las últimas décadas, la consolidación de lo que ha venido a denominarse como constitucionalismo sintético en el marco de la UE ${ }^{11}$, ha ido transformando algunos aspectos constitucionales económicos que tradicionalmente venían interpretándose como mutaciones aceptables dentro del esquema delineado por nuestra Norma Fundamental ${ }^{12}$. La inclusión del nuevo art. $135 \mathrm{CE}$, implica no sólo el reconocimiento del hecho de la integración de la Constitución Española en un ordenamiento que se está demostrando jerárquicamente superior, sino la prescripción de una forma distinta a como aquella venía entendiendo las relaciones entre el Estado, la sociedad y el mercado.

\subsection{La reforma del art. 135 CE y la problemática conceptual sobre la constitución económica}

Hacer una aproximación a la problemática sobre la constitución económica requeriría seguramente un trabajo separado al que proponemos. Por lo tanto, a lo largo del texto se irán haciendo apuntes doctrinales sobre una base que conviene tener clara desde el principio. En este sentido, las polémicas en torno a la constitución económica, prácticamente desde su fundación como noción autónoma a caballo entre el derecho público y la economía en la República de Weimar, han sido fundamentalmente dos, aunque en puridad sólo nos interese una ${ }^{13}$.

La primera es si realmente pueden existir, dentro del principio de unidad de la Constitución como norma jurídica producto de una decisión del poder

${ }^{10}$ Lo cual no quiere decir que de forma particular, esta cuestión no haya sido abordada en diferentes trabajos, entre los cuales merece la pena destacar la obra colectiva GARCíA Herrera, M.A. (dir.), El constitucionalismo en la crisis del Estado social, Universidad del País Vasco, Bilbao, 1997.

${ }^{11}$ MenÉndez, A.J. y Fossum, J.E., The Constitution's Gift: A Constitutional Theory for a Democratic European Union, Rowman \& Littlefield Publishers, Londres, 2011.

${ }^{12}$ En el contexto de la doctrina española, un acercamiento a esta cuestión, en GARCía Gestoso, N., Soberanía y Unión Europea (Algunas cuestiones críticas desde la Teoría de la Constitución), Atelier, Barcelona, 2004, p. 331 y ss.

${ }^{13}$ Sobre esta cuestión, donde se hace un resumen sobre las diferentes posiciones de autores clásicos como Schmitt, Neumann o Heller, ver CocozzA, F., «Riflexioni sulla nozione di "Costituzione economica"», Il diritto della economia, núm. 1, 1992, pp. 71-90. 
constituyente, núcleos constitucionales -como las normas referidas a la economía- que en última instancia adquieran autonomía propia y se opongan a los principios fundamentales de la propia Constitución. Esta cuestión, planteada inicialmente por SCHMITT y desarrollada posteriormente por FoRSTHOFF, ha sido superada por los teóricos del Estado del bienestar (tanto en Italia como en Alemania) que han venido señalando que la constitución económica no tiene por qué oponerse a la Constitución como un todo. Es más, está prácticamente aceptado que la superioridad de la Constitución política no sólo opera en un posible debate entre la democracia representativa-democracia corporativa, sino que tiene la función de proyectar sus efectos al modelo global contenido en la Constitución ${ }^{14}$.

Para nuestros objetivos, resulta más fecundo el debate referido a la conceptualización o definición del término «constitución económica», pues los problemas derivados de la reforma del art. $135 \mathrm{CE}$, pueden venir determinados por antinomias materiales entre los principios del Estado social (o del bienestar) reconocidos en la $\mathrm{CE}$ y los postulados del constitucionalismo regulador comunitario ${ }^{15}$. De este modo, por un lado se entenderá, en una definición dominante en nuestro entorno jurídico-cultural, que la constitución económica describe, desde un punto de vista neutral, las disposiciones de la Constitución formal relativas a las relaciones económicas. Este concepto, utilizado en alguna ocasión por nuestro Tribunal Constituciona ${ }^{16}{ }^{16}$ remite a la idea de que la constitución económica contenida en la Norma Fundamental no garantiza necesariamente un modelo económico ni lo sanciona, simplemente permite el funcionamiento de todos los sistemas que se ajustan a los parámetros constitucionales y sólo excluye aquellos que sean contradictorios con los mismos ${ }^{17}$.

Frente a este concepto, aparece la noción sustancial de constitución económica, que presupone la remisión a un modelo constitucionalmente recibido (y así, España, según el art. 1.1 de la Constitución, se constituye en un Estado social y democrático de Derecho). Este modelo actúa normativamente, es decir, disciplinando y dotando de coherencia a las normas, no solo constitucionales, impidiendo por tanto su consideración autónoma y hermenéuticamente neutral. Ahora bien, los problemas surgen cuando se trata de caracterizar el contenido sustancial de la constitución económica, pues la historia muestra que entre una economía centralizada y monopolística y una

${ }^{14}$ Ehmke, H., «Economía y Constitución», Revista española de Derecho Constitucional Europeo, $\mathrm{n}^{\circ} 5$, 2006, p. 376, http://www.ugr.es/ redce/

${ }^{15}$ Una aproximación a esta cuestión, en el trabajo de LASA LóPEz, A., Constitución económica y derecho al trabajo en la Unión Europea, Comares, Granada, 2011.

${ }_{16}$ SSTC 1/1982, de 28 de enero; y 36/1981, de 12 de noviembre.

17 Entre la doctrina española, Martín Retortillo BaQuer, S., Derecho administrativo económico, Vol.1, La Ley, Madrid, 1988, p. 29. En la doctrina alemana, ReIcH, N., Mercado y derecho, Ariel, Barcelona, 1985, p. 74. Bassols Coma, M., Constitución y sistema económico, ob. cit., p. 17, que pone énfasis en la noción de sistema. 
pura de mercado hay un trecho tan grande, que incluso podrían ponerse en entredicho los principios del Estado democrático de Derecho.

A pesar de lo que se ha venido señalando, la contraposición entre el Estado social y el Estado mínimo es una operación ideológica en la medida en que resulta difícil identificar formas de poder que hayan articulado de forma ideal ambas concepciones en la práctica. La constitucionalización de los países del Sur de Europa primero (Grecia, Portugal y España), y del Este después (todos los países que formaron parte de la órbita soviética), muestra la incorporación de modelos socioeconómicos en crisis y la ratificación de economías liberales que escapaban, como es lógico, de cualquier forma de planificación política. Y así, como consecuencia de la evolución histórica y del planteamiento de nuevas condiciones impuestas por la globalización y los fenómenos de institucionalización regional, nos encontramos con constituciones económicas que mutan, se van transformando en la búsqueda de una mejor adaptación al medio económico, y por lo tanto de un crecimiento sostenido.

Pese a lo dicho, los recientes acontecimientos provocados por la crisis, invitan a pensar que no es conveniente abandonar por completo la noción sustancial de constitución económica. La constitucionalización de Europa (entiéndase, de la UE), la inserción del derecho comunitario en los ordenamientos nacionales, ha significado la superposición de una nueva constitución material sobre las constituciones económicas formales nacionales ${ }^{18}$. De ello hablaremos a lo largo del trabajo. En todo caso, aún adoptando una perspectiva neutralista, que avalase las mutaciones que la integración europea ha producido en las Constituciones nacionales en el ámbito económico, no hay posibilidad de eludir el contenido axiológico (fundado en la construcción de un mercado único) que contienen los Tratados de la UE. Como estamos pudiendo comprobar, la crisis actual está teniendo como resultado una aplicación estricta de los valores y principios contenidos en la constitución económica europea, particularmente en el Título VIII del TFUE: despolitización de las prácticas monetarias, recortes sociales, reformulación de servicios públicos, reconfiguración de los sistemas de pensiones y reforma del mercado laboral, todo ello a golpe de decisión informal del Consejo Europeo y el Eurogrupo y de insinuaciones del Banco Central Europeo (en adelante BCE) a los gobiernos de los Estados miembros con problemas. La reforma del art. $135 \mathrm{CE}$ es la culminación formal de una serie de cambios que obviamente deberán de ser juzgados desde la perspectiva del paso del tiempo y de los análisis constitucionales más sosegados.

\subsection{El sistema competencial de la Unión Europea en materia económica}

${ }^{18}$ En el caso español, cuestión puesta de relieve hace ya tiempo, por HERRERO DE Miñón, M., «La constitución económica: desde la ambigüedad a la integración», Revista Española de Derecho Constitucional, núm. 57, 1999, pp. 11-32. 
A casi nadie se le escapa que la reciente reforma del art. $135 \mathrm{CE}$ viene provocada por las tensiones en la deuda soberana de nuestro país durante el verano de 2011. Sin embargo, obvio resulta que la nueva disciplina presupuestaria integrada en nuestra Constitución proviene de las exigencias establecidas normativamente en los Tratados comunitarios y en el derecho derivado. Que la reforma ha estado provocada por una crisis de confianza, se colige del hecho de que España no ha sido un Estado especialmente incumplidor del Pacto de Estabilidad y Crecimiento (en adelante PEC) ${ }^{19}$. Sin embargo, esta ya no es una cuestión que deba preocuparnos en exceso, porque la reforma de la Constitución funciona hacia el futuro, y lo que conviene explicar son las potencialidades de los límites incluidos en el art. $135 \mathrm{CE}$, desde el punto de vista presupuestario y de capacidad de endeudamiento de un país. El simbolismo de la reforma, su capacidad para constreñir la autonomía institucional de España como Estado miembro de la UE, quedará precisado, fundamentalmente, por la capacidad que las normas comunitarias tengan para desplegar su eficacia sobre el procedimiento presupuestario establecido en el Título VII de la CE.

Para ello, es necesario hacer alguna alusión al marco competencial sobre el que se asienta el PEC en los Tratados comunitarios. El PEC se encuentra regulado primariamente en el Título VIII del TFUE y en el Protocolo $\mathrm{n}^{\mathrm{o}} 12$ anejo a dicho Tratado ${ }^{20}$. Por lo tanto, se encuadra en lo que genéricamente el art. 5 TFUE denomina como competencias de coordinación. Antes de entrar a analizar las competencias en materia económica contenidas en los Tratados, conviene realizar una aclaración general con respecto al sistema competencial de la UE.

A nuestro modo de ver, el principio de atribución reconocido en el art. 5.1 del Tratado de la Unión Europea (en adelante TUE) es el principio esencial que rige el reparto de poder entre la UE y los Estados miembros. Esta idea queda reforzada por la exigencia constitucional de que la UE cuente para la adopción de cada acto jurídico con el correspondiente fundamento jurídico, sea expreso o cuando menos deducible en sede interpretativa del derecho comunitario ${ }^{21}$. No es menos cierto, sin embargo, que la tensión entre criterios materiales, fundamentalmente contenidos en la parte que regula las políticas de la UE, y funcionales, vinculados a la definición de las misiones y los objetivos de ésta, ha venido dificultando la actuación del

${ }_{19}$ Así lo pone de manifiesto TAJADURA TEJADA, J., «Reforma constitucional e integración europea», Claves de razón práctica, núm. 216, 2011.

${ }^{20}$ Amén de otra serie de normas derivadas (fundamentalmente reglamentos) que irán siendo citadas a lo largo del artículo.

${ }^{21}$ El principio viene siendo afirmado periódicamente por el Tribunal de Justicia de la UE: asunto C-6/64, Flaminio Costa v. E.N.E.L., Sentencia del TJCE de 15 de julio de 1964; asunto C-267/95, Merck v. Primecrown, Sentencia del TJCE de 5 de diciembre de 1996. 
principio de atribución como instrumento de distribución competencial ${ }^{22}$. En este sentido, aunque el TFUE introduzca como novedad un modelo de lista o catálogo material al modo federal, la prevalencia del derecho comunitario (transmutada en primacía) y el peso de los objetivos funcionales (art. 3 TUE) siguen siendo elementos decisivos en la relación Estados-UE, ello porque las cláusulas de flexibilidad competencial incluidas en el ordenamiento comunitario tienen como jueces últimos a los propios Estados miembros en el seno del Consejo de Ministros ${ }^{23}$. La compleja realidad política y económica supranacional hace imposible dividir las materias en compartimentos estancos, y muy difícil suponer que los Tratados pretendan eludir la existencia de solapamientos regulatorios derivados del ejercicio de competencias distintas.

Esta visión es especialmente fecunda en el ámbito del gobierno de la economía, no solo de la construcción del mercado único. De hecho, autores como GUARINo han venido señalando que lo importante del «eurosistema», entendido éste como el ámbito de relaciones de poder entre los Estados miembros y la UE a partir de la concreción de la moneda única, no es la categorización de competencias, sino la disposición institucional (y en el fondo política) que permite conectar las propias competencias con los objetivos establecidos en los Tratados ${ }^{24}$.

Como acabamos de señalar, el PEC se encuentra regulado en el art. 126 TFUE y en el Protocolo $\mathrm{n}^{\circ} 12$ anejo a los Tratados, donde se concretan sus niveles de referencia. Por lo tanto, puede incluirse en el conjunto de competencias denominadas como de coordinación o no regulativas, y que hacen referencia a las políticas económicas y de empleo de la UE (art. 5 TFUE). Genéricamente pueden ser definidas como de apoyo y surgen en los nuevos ámbitos de acción establecidos desde el Acta única Europea y el Tratado de Maastricht. El lenguaje que utiliza el art. 5 TFUE es recurrente pero enigmático: la UE coordinará las políticas económicas, sociales y de empleo, con especial atención a los países que forman el euro. Sin embargo, el conjunto de decisiones formales e informales que desde las instituciones europeas se vienen adoptando en los dos últimos años, como resultado de la crisis, parece indicar que nos encontramos ante una categoría competencial que se constituye como un tertium genus en el marco de la dialéctica

22 WeILER, J.H.H., «L'Unione e gli Stati membri: competenze e sovranità», Quaderni Costituzionali, núm. 1, 2000.

${ }^{23}$ En apoyo de esta tesis, QuAdra SAlCEDo-JANini, T. de la, El sistema europeo de distribución de competencias (Garantías políticas y garantías jurídicas en un ámbito propio de decisión de los Estados miembros de la Unión Europea), Thomson-Civitas, Madrid, 2006. Una visión crítica con este punto de vista, en Arroyo GIL, A., «Los principios de competencia y prevalencia de los conflictos competenciales», Revista Española de Derecho Constitucional, núm. 80, 2007, pp. 407-435.

${ }^{24}$ Guarino, G., Eurosistema: analisi e prospettive, Giuffrè, Milán, 2006, en especial pp. 27-60. 
constitucional comunitaria, similar en el resultado a los modelos federales comparados (proceso de centralización de las competencias económicas), pero con unos medios y funciones públicas mucho más modestos, lo que provoca una incapacidad manifiesta para acometer con eficacia los problemas que surgen a nivel supranacional (lo que llamamos indeterminación institucional) $)^{25}$.

Se ha señalado, en todo caso, que al situarse fuera del sistema genérico de distribución de competencias de la UE, estamos ante un nivel de intervención política residual, que define la coordinación como una aproximación institucional débil y que por lo tanto sigue atribuyendo a los Estados miembros los elementos sustanciales de la política económica: asignación de bienes y servicios públicos, redistribución de la renta y estabilización y crecimiento económico ${ }^{26}$. Frente a este enfoque residual, en nuestra opinión el gobierno de la economía europeo adquiriría una gran trascendencia, por lo que a pesar de configurarse como una competencia compartida, aparece con renglones propios en los Tratados, lo que a la vez implica un instrumental normativo e institucional distinto. Nominalmente, la insistencia en el término «coordinación» que hacen los Tratados no debe llevarnos a despiste, al fin y al cabo la propia Constitución española, como otros modelos federales, señala en su art. 149.1.13 que el Estado tendrá competencia exclusiva para dictar las bases y coordinación de la planificación general de la actividad económica. Ello ha producido, como bien se sabe, que pese a que los Estatutos de Autonomía califiquen algunas competencias sobre materias de carácter económico como exclusivo y a que el Estado no tenga competencias sectoriales específicas sobre dichas materias, aquél pueda influir siempre sobre la ordenación y el desarrollo de dichas actividades mediante el ejercicio de competencias horizontales en este campo de la realidad ${ }^{27}$.

De este modo, el art. 5 TFUE se presentaría más bien como un título horizontal, funcional o transversal, lo que supone la posibilidad de que la UE afecte, al regular para alcanzar el objetivo de una economía social de mercado competitiva, sectores materiales muy diversos. Sectores que como en el que caso del federalismo, pueden estar regulados a partir de competencias propias y distintas (en muchos de los casos en régimen de exclusividad) de los Estados miembros.

${ }^{25}$ Hemos abordado esta cuestión en Miguel Bárcena, J. de, El gobierno de la economía en la Constitución europea. Crisis e indeterminación institucional, Bosch, Barcelona, 2011.

${ }^{26}$ Por ejemplo, entre nuestra doctrina, Parejo Alfonso, L., «La Directiva Bolkenstein y la Ley paraguas: ¿Legitima el fin cualesquiera medios para la reconversión de un Estado "autoritativo"?», Revista española de derecho europeo, núm. 32, 2009, pp. 413467.

${ }^{27}$ Carrasco, M., El reparto de competencias entre el Estado y las Comunidades Autónomas sobre la actividad económica, Tirant lo Blanch, Valencia, 2005. 
Así, técnicamente, cuando la UE actúa de manera ordinaria o extraordinaria bajo el paraguas del art. 5 TFUE y del Título VIII que lo desarrolla en el mismo Tratado, lo hace bajo los criterios de un esquema competencial compartido o de lo que podríamos denominar como «concurrencia práctica» ${ }^{28}$. Pero no en el sentido de que los Tratados comunitarios atribuyan a la UE la legislación sobre una materia y los Estados miembros tengan que asumir constitucionalmente la ejecución o el desarrollo de la normativa reguladora de la misma materia: lo que el ente comunitario lleva a cabo es la disciplina de determinados elementos y magnitudes de política macroeconómica, que integra un marco de condiciones generales en el cual deben desarrollarse todas las actividades económicas particulares. Con ello, se concretan los objetivos de política económica general para la zona euro que deben alcanzarse en el ejercicio de las actividades económicas concretas y se prevén medidas con el fin de encauzar el desarrollo de tales actividades al cumplimiento de dichos objetivos. También, obviamente, en el marco del PEC, que es el instrumento concreto del gobierno de la economía comunitaria que más nos interesa analizar a raíz de la reforma del art. 135 CE.

\subsection{El Pacto de Estabilidad y Crecimiento en la constitución económica europea}

El nuevo art. $135 \mathrm{CE}$ no nombra el PEC, aunque resulta obvia su influencia en la reforma constitucional realizada en agosto de 2011. En todo caso, en la mal llamada exposición de motivos de la nueva norma, se señala que «El Pacto de Estabilidad y Crecimiento tiene como finalidad prevenir la aparición de un déficit presupuestario excesivo en la zona euro, dando así confianza en la estabilidad económica de dicha zona y garantizando una convergencia sostenida y duradera de las economías de los Estados Miembros». Conviene, antes de realizar juicio alguno sobre la compatibilidad del PEC con el régimen constitucional de nuestro país, analizar qué papel juega el PEC en la constitución económica europea, cuál es su origen político y qué objetivos tiene con respecto a los instrumentos del gobierno de la economía planteado en términos supranacionales.

El PEC se encarga de controlar los déficits y la deuda pública de los Estados miembros, es decir, el uso de la competencia presupuestaria que ha-

${ }^{28}$ En realidad, con excepción de lo que el TFUE reconoce como competencias exclusivas, o de aquellas competencias compartidas que como la agricultura, se han ido transformando en «exclusividades derivativas» por la profusa regulación realizada en sede comunitaria, todo lo que en el TFUE entra dentro del poder "compartido» entre la UE y los Estados miembros, puede considerarse como una formulación competencial de tipo concurrencial, al estilo del art. 75 de la Ley Fundamental de Bonn. Ello porque el art. 2.2 TFUE se señala claramente que «[...] Los Estados miembros ejercerán su competencia en la medida en que la Unión no haya ejercido la suya [...]». Sobre esta cuestión en general, en el ámbito comparado norteamericano, QuAdRA-SALCEDO JANINI, T. de la, Unidad económica y descentralización política, Tirant lo Blanch, Valencia, 2004. 
gan los correspondientes gobiernos y parlamentos nacionales. Se constituye como el paradigma de lo que podría denominarse como pretensión de control jurídico de la economía. Como bien se sabe, originalmente la Unión Económica y Monetaria (en adelante UEM) atribuía al BCE la misión de luchar contra la inflación, pero no establecía ningún mecanismo automático para limitar el déficit excesivo. Por ello, Alemania presentó la propuesta de suplementar el Tratado con nuevos requerimientos fiscales: una mayor restricción presupuestaria para asegurar que el techo del 3 por 100 del déficit público no sería superado en ninguna fase del ciclo, y la incorporación de un mecanismo de sanción automático en caso de incumplimiento de la norma. Alemania, que fue la impulsora del PEC a través del por aquel entonces ministro de finanzas, T. WAIGEL, explicó que las ventajas de la integración monetaria sólo llegarían si los países miembros mantenían sanas prácticas fiscales, tal y como expresan los arts. 109 y 110 de su Ley Fundamenta ${ }^{29}$. Seguramente, WaIGEL también tenía en mente las teorías del economista Mundell, autor intelectual de las áreas monetarias óptimas, y que desde el principio advirtió de la imposibilidad de crear una moneda única con sistemas fiscales diversificados ${ }^{30}$. Por esta razón, los países que entrasen en la tercera fase del proceso de integración, deberían firmar un «Pacto de Estabilidad para Europa», el cual, sin pretender eliminar la soberanía fiscal de los países, suponía una declaración explícita de su compromiso con la estabilidad presupuestaria como medio para el crecimiento económico y la creación de empleo.

El PEC tiene por tanto, en origen, un claro objetivo de coordinación. En un área donde existe una moneda única y una política cambiaria controlada por una sola institución, el hecho de que la política fiscal sea manejada discrecionalmente por los gobiernos nacionales puede facilitar que los países incurran en déficit, déficit cuyas consecuencias se distribuirían negativamente entre todos los países miembros que comparten la zona euro, tal y como estamos teniendo oportunidad de comprobar en la actualidad ${ }^{31}$. Ahora bien, conviene recordar, en primer lugar, que al margen de que los umbrales del PEC puedan estar más o menos sólidamente fundados en la teoría económi$\mathrm{ca}^{32}$, resulta evidente que su filosofía expresa un tipo de intervención que vin-

${ }^{29}$ Buti, M., Franco, D. y Ongena, H., «Fiscal Discipline and Flexibility in EMU: The Implementation of the Stability and Growth Pact», Oxford Review of Economic Policy, Vol. 14, núm. 3, 1998, pp. 81-97.

30 Robert Mundell es Premio Nobel de economía desde 1993. Su trabajo sobre las áreas monetarias óptimas puede consultarse en MundeLl R., «A Theory of Optimun Currency Areas», en Krauss, M. (Ed.), The Economics of Integration, George Allen \& Unwin LTD, Londres, 1973.

31 Carrasco Monteagudo, I. y Pardo García, I., «El Pacto de Estabilidad y Crecimiento. Implicaciones para una Europa ampliada», Nuevas tendencias en política fiscal (ICE), núm. 835, 2007, p. 67.

32 No es la opinión de Eichengreen, B. y Jefrry Frieden, B., «The Political Economy of European Monetary Unification», en Eichengreen, B. y Jeffry Frieden, B. (eds.), The Political Economy of European Monetary Unification, Westview Press, Boulder, 2001. 
cula la estabilidad con la autonomía del mercado y la disciplina monetaria, mediante el traslado del gobierno de la economía al mero control jurídico de niveles o parámetros macroeconómicos. El cumplimiento de dichos niveles, que pretende asegurarse con la amenaza de sanciones, debería servir por sí solo para mantener unos niveles de crecimiento relevantes.

En general, el PEC sirve a quienes valoran los efectos crowding-out de la actividad del Estado frente al sector público, o a quienes defienden que la estabilidad presupuestaria o una adecuada gestión de las finanzas públicas estimula el crecimiento. Esta corriente de pensamiento neoliberal afianza su dominio a lo largo de la década de los años ochenta, por las necesidades de financiación de las administraciones públicas y el elevado desempleo a principios del período, tras décadas de déficit excesivo. En el caso del PEC, estamos por tanto ante una concreción evidente de la teoría de los marcos fiscales, que busca una deliberada limitación de la soberanía parlamentaria en materia presupuestaria y responde a un presunto defecto de los sistemas democráticos: su espontánea inclinación, como resultado de la competencia por el voto, a gastar más de lo que ingresan e incurrir en déficits presupuestarios crónicos ${ }^{33}$.

Lo de menos es discutir ahora si el PEC ha sido un instrumento útil para la llamada gobernanza económica de la UE. Desde luego, la sombra de las sanciones no ha evitado el incumplimiento moderado, como es el caso de Francia o Alemania, o flagrante, como ha sido el caso más reciente de Grecia, de los límites de endeudamiento y déficit público establecidos en el mismo. Lo importante es recordar que el PEC se incardina en las competencias de coordinación, lo que en principio implicaría la posibilidad de que los Estados miembros, a través de sus gobiernos, lo llevasen al terreno del consenso intergubernamental, que al menos aseguraría una cierta preponderancia del proceso político en el marco del Consejo de la UE. Sin embargo, la primacía de la política sólo tuvo su virtualidad en el marco del fallido proceso sancionador a Francia y Alemania en el año $2003^{34}$. El PEC no contenía fórmulas de flexibilidad para abordar de forma diferenciada las exigencias de las áreas económicas en las que se articula la $\mathrm{UE}^{35}$. Por el contrario, se ha mostrado

33 Buchanan, J., Democracy in Deficit. The Collected Works of James M. Buchanan: Volume VIII, Liberty Fund, Indianapolis, 2000.

${ }^{34}$ Angel, B., «Le Pacte de Stabilité est-il mort?», Revue du Marché Commun et de l'Union Européenne, núm. 476, 2004, pp. 145-150.

${ }^{35}$ Decimos no contenía, porque con la nueva reforma de la gobernanza económica publicada en noviembre de 2011, se prevén cláusulas de escape de la aplicación estricta del PEC mediante, por ejemplo, la definición más precisa de las circunstancias excepcionales expresadas tanto en el art. 126.2 a) como en el art. 122.2 TFUE. Y así, se habla de «crisis económica grave en la zona euro o en el conjunto de la UE» o de un «acontecimiento inusitado sobre el que el Estado miembro afectado no tenga ningún control y que tenga efectos considerables sobre la situación de su hacienda pública», como presupuestos para que una desviación significativa de gasto pueda no ser considerada como sancionable desde el punto de vista de los parámetros del PEC. Ambos supuestos en los arts 5.1 y 10.3 
como herramienta muy útil a la hora de absorber competencias económicas de las Constituciones nacionales, mediante las constricciones que afectan especialmente a los mecanismos de intervención en la economía de los Estados miembros, esto es, la función presupuestaria y la política fiscal. La limitación de la política presupuestaria nacional a los parámetros macroeconómicos del PEC implica en realidad una limitación global de la constitución económica de los Estados miembros, que a través de la mera coordinación europea aceptan reconfigurar sus políticas públicas y sociales de acuerdo a los niveles de endeudamiento que indirectamente prescribe aquél.

Pero el reemplazo de la política presupuestaria y fiscal nacional, por las reglas económicas prefabricadas del PEC, no sólo demuestra la dificultad de seguir interpretando el reparto competencial entre el Estado y la Unión a través del principio de atribución, sino que revela la precaria legitimidad política del conjunto de la construcción europea en esta materia ${ }^{36}$. Es cierto que la inclusión de la filosofía del PEC en las constituciones nacionales, tal y como por ejemplo ha hecho España con el art. $135 \mathrm{CE}$, relaja la tensión producida por la fuga de soberanía presupuestaria que se produce desde el Estado a la UE. Sin embargo, con iniciativas como ésta sólo se resuelve la mitad de la paradoja, pues el problema sigue residiendo entonces en crear un espacio institucional que a nivel europeo refuerce en términos democráticos el propio PEC, y las actuaciones que en base a éste limiten tanto las normas del sistema político comunitario como, ya definido en términos subalternos, el poder institucional nacional.

\section{LA RECEPCIÓN DEL PRINCIPIO DE ESTABILIDAD PRESU- PUESTARIA EN LOS ESTADOS MIEMBROS, CON ESPECIAL REFERENCIA A ESPAÑA Y ALEMANIA}

El equilibrio entre los ingresos y los gastos de un presupuesto es cuestión que puede deducirse de las prácticas financieras y hacendísticas de los países desarrollados, desde que a partir de 1970, las sucesivas crisis han ido reduciendo la capacidad fiscal de los poderes públicos para atender las distintas dimensiones de las políticas públicas ${ }^{37}$. La detracción de recursos del capital y el trabajo, implica en todo caso que esos mismos recursos van a volver a la sociedad en las distintas formas que prevea la propia Constitución y las normas derivadas encargadas de configurar la concertación entre

del Reglamento (CE) no 1466/97 del Consejo, de 7 de julio de 1997, relativo al reforzamiento de la supervisión de las situaciones presupuestarias y a la supervisión y coordinación de las políticas económicas, reformado por el Reglamento (UE) n 1175/2011 del Parlamento Europeo y del Consejo, de 16 de noviembre de 2011, Diario Oficial de la Unión Europea, núm. L 306, de 23 de noviembre de 2011.

${ }^{36}$ Rivosecchi, G., «El gobierno económico en la Unión Europea», Revista española de Derecho Constitucional Europeo, núm. 8, 2007, pp. 139-151.

${ }^{37}$ Clásico, en este sentido, el trabajo de O'Connor, J., The Fiscal Crisis of the State, St. Martin's Press, Nueva York, 1971. 
el sistema político y los diferentes subsistemas que tratan de beneficiarse de las prácticas redistributivas. Por lo tanto, la idea de equilibrio presupuestario desplegado en el marco del Estado social o del bienestar era relativa, pues el crecimiento dependía en buena medida de la capacidad de endeudamiento de los poderes públicos y su participación en el ciclo económico. Aún con todo, por ejemplo la Constitución española, cuya constitución económica presentaba ya características de un constitucionalismo social en crisis $^{38}$, incluyó originalmente una regla procedimental propia de los «marcos fiscales» de los que hablábamos en el epígrafe anterior, pues el art. 134.6 señala que «toda proposición o enmienda que suponga aumento de los créditos o disminución de los ingresos presupuestarios requerirá la conformidad del Gobierno para su tramitación». Tal disposición, que nuestro Tribunal Constitucional ha consignado a las iniciativas posteriores a la aprobación de la Ley de Presupuestos, ha sido utilizada de manera profusa en legislatura que ha conducido a la reforma del art. $135 \mathrm{CE}^{39}$.

La filosofía del PEC y del nuevo art. $135 \mathrm{CE}$ es bastante diferente a este planteamiento. Como ya hemos señalado, la idea de imponer unas reglas fiscales y de endeudamiento a todos los Estados que participasen en la UEM, partió de Alemania. En dicho país, el gusto por la contención monetaria, las cuentas públicas saludables y la limitación del endeudamiento, ha sido históricamente algo más que un objetivo político cargado de buenos propósitos. Analicemos esta cuestión con un poco más de detenimiento.

\subsection{Alemania, la estabilidad presupuestaria y el límite de endeudamien- to: filosofía económica y constitucionalización}

La inclusión en el art. 110 de la Ley Fundamental de la frase «El presupuesto federal deberá ser equilibrado en sus ingresos y gastos» debe ser observada desde un doble punto de vista. El primero, obviamente, el histórico anteriormente comentado. Acostumbrados a vivir apegados a los acontecimientos, casi nadie recuerda que el modelo de Banco Central independiente y la necesidad de tener unos poderes públicos no endeudados surge en Alemania por el uso que de estas variables se hizo en el periodo de entreguerras. Económicamente, la monetización y el endeudamiento masivo provocaron diversos episodios de hiperinflación producidos por la pérdida del poder adquisitivo destinado a las reparaciones derivadas del Tratado de Versalles y la politización del Reichsbank ${ }^{40}$. En este sentido, no resulta vano recordar que la situación de descontrol económica permitió el ascenso del irracionalismo po-

${ }^{38}$ Maestro Buelga, G., La Constitución del trabajo en el Estado social, Comares, Granada, 2002.

39 Sobre esta cuestión, ver, MartínEz LAGo, M.A., «El control parlamentario sobre el presupuesto público», Presupuesto y gasto público, núm. 48, 2007, pp. 129-143.

${ }^{40}$ Widdig, B., Culture and Inflation in Weimar Germany, University of California Press, Berkeley, 2001; y Feldman, G.D., The Great Disorder, Oxford University Press, 1997. 
lítico nazi, que lejos de abandonar las prácticas que venimos reseñando, puso el conjunto de la riqueza alemana al servicio de un proyecto imperialista que utilizaba la planificación económica para alcanzar sus objetivos políticos ${ }^{41}$.

Durante este periodo, la Escuela de Friburgo ya venía trabajando sobre un modelo neutro que recondujese las relaciones entre la política y la economía en clave liberal ${ }^{42}$. Aún con todo, el mercado perdió en el ordoliberalismo alemán sus connotaciones de instancia natural ajena a la intervención política, para convertirse en objeto de articulación institucional. Por ello la economía devino en problema constitucional. Problema que la Ley Fundamental de Bonn trató de superar eliminando las prácticas del periodo de entreguerras y limitando los modelos planificados que asomaban en el socialismo real que llamaba prácticamente a su puerta ${ }^{43}$. Así, en la Constitución alemana de 1949 la economía de mercado aparece ya como la única conciliable y conforme a los principios del Estado de Derecho, constituyéndose en referencia constitucional y en modelo normativo de ordenación de la economía en general.

El modelo de constitución económica alemana se trasladó a la forma en que se concibió el proyecto de integración europea durante bastantes décadas. En el planteamiento ordoliberal, la Comunidad Europea gozaba originalmente de una legitimidad independiente de la propia de las instituciones constitucionales y democráticas de los Estados miembros, en la medida en que las disposiciones de los Tratados prescribían un orden basado en el derecho, cuya función consistía en garantizar las libertades económicas y proteger la libre competencia mediante instituciones supranacionales. Implícitamente, ello implicaba la imposición de límites a la propia Comunidad: sus eventuales políticas económicas discrecionales serían consideradas contrarias al pacto constitucional alcanzado por los Estados miembros fundadores, que incluía la apertura de las economías nacionales (sólo empañada por el pecado original de la Política Agraria Común), la existencia de una serie de normas que prohibían las políticas discriminatorias, y la aceptación de un sistema de libre competencia ${ }^{44}$.

Ciertamente, en las negociaciones del Tratado de Roma, en 1956, habían triunfado las tesis de la economía social de mercado alemanas ${ }^{45}$, lo que suponía el establecimiento del dualismo institucional en lo que respecta a

${ }^{41}$ Baste recordar, en este sentido, el clásico trabajo de Neumann, F., Behemoth. Pensamiento y acción en el nacional-socialismo, FCE, México, 1983, que definió el nazismo como un monopolio capitalista totalitario.

42 Di Nella, L., «La scuola di Friburgo, o dell'ordoliberalismo», en VV.AA., Diritto ed economia. Problemi e orientamenti teorici, Cedam, Milán, 1999, pp. 171-227.

${ }^{43}$ EUCKEN, W., «El problema político de la ordenación», en La economía de mercado, Sociedad de Estudios y Publicaciones, Madrid, 1963, pp. 25-80.

44 Streit, M. E. y Mussler, W., «The Economic Constitution of the European Community. From "Rome" to "Maastricht"», European Law Journal, Vol. 1, núm. 1, 1995, pp. 5-30.

${ }^{45}$ Sobre este concepto, Muller-Armack, A., «Las ordenaciones económicas desde el punto de vista social», en La economía de mercado, ob. cit., pp. 81-116. 
la constitución económica: el mercado se construiría en Europa, las políticas socioeconómicas permanecerían en los Estados. Se trataba de escapar de formas económicas planificadas, a través de un mayor control estatal en los ámbitos de los fallos del mercado y una política social que hiciese eficiente el desarrollo de los diferentes factores productivos. Sin embargo, el desarrollo del proceso de integración, paralelo a las sucesivas crisis que iban a surgir en el modelo capitalista desde la década de 1970, propició una progresiva aproximación entre los ordenamientos materiales de la UE y de los Estados miembros, cuya culminación fue sin duda el Tratado de Maastricht. El Tratado de la UE supuso la culminación de una serie de procesos normativos provocados por las invasiones del mercado comunitario, la expansión de la constitución antidiscriminatoria formulada por el art. 18 TFUE y la incorporación de ámbitos competenciales por parte de las instituciones europeas a través de mecanismos ya mencionados ${ }^{46}$. No es casualidad que a partir de este momento, vayan surgiendo las diferentes aportaciones doctrinales en torno al constitucionalismo multinivel, que desde la propia Alemania han tratado de interpretar el modo en el que los Tratados comunitarios y las Constituciones nacionales se van entrelazando progresivamente hasta materializar una misma «Unión constitucional» ${ }^{47}$.

La llegada de la UEM, construida a partir del acuerdo alcanzado en Maastricht, obligó, ya lo hemos visto, a establecer mecanismos de estabilización fiscal en el conjunto de la política económica que se desarrollaba en la zona euro. Apareció así el PEC, que era el complemento perfecto para un modelo de constitución económica muy similar a la contenida en la Ley Fundamental de Bonn, pues otorgaba un papel estelar a la estabilidad monetaria, la lucha contra la inflación y las políticas de gasto moderadas ${ }^{48}$. Sin embargo, en el marco de la aplicación de los planes de estabilidad macroeconómica diseñados para integrarse en el euro, Alemania (al igual que Francia) no consiguió cumplir con las expectativas formalizadas en el PEC, y así en el año 2003, la Comisión abrió un procedimiento por déficit excesivo que sólo pudo ser frenado por la acción conjunta de Francia con la propia Alemania en el seno del Consejo de la UE. La crisis se resolvió con una sentencia del Tribunal de Justicia de la UE (en adelante TJUE) puramente procesal, que debilitó la eficacia jurídica del PEC, puso en evidencia el proceso de subordinación del ejecutivo comunitario frente a la voluntad de los Estados miembros y dejó en mal lugar al país que más interés había puesto en articular un sistema

46 Joerges, C., «¿Qué tiene de social-demócrata la constitución económica europea?», Revista Española de Derecho Constitucional, núm. 73, 2005, pp. 9-53.

${ }^{47}$ Pernice, I., «Multilevel constitutionalism and the Treaty of Amsterdam: european constitution-making revisited?», Common Market Law Review, Vol. 36, núm. 4, 1999.

${ }^{48}$ Baste recordar que el art. 88 de la Ley Fundamental caracteriza materialmente al Banco Central, al señalar que «es independiente y está al servicio del objetivo prioritario de garantizar la estabilidad de los precios». 
de sanciones para los miembros de la UEM que no cumpliesen con los niveles de déficit y de endeudamiento establecidos en el actual art. $126 \mathrm{TFUE}^{49}$.

Aprovechando la modificación de las relaciones de poder entre los centros principales de decisión política a nivel federal y de Land que llevó a cabo, la reforma constitucional del federalismo alemán de 2006 introdujo algunos cambios en la constitución financiera ${ }^{50}$. Particularmente, el nuevo art. 109.5 supuso la inclusión en la Ley Fundamental de los compromisos adquiridos por la República Federal en virtud del PEC para el mantenimiento de la disciplina presupuestaria. El art. 109.5 regula así la responsabilidad que a la Federación, por un lado, y a los Länder, por otro, corresponde ante un eventual incumplimiento de las obligaciones comunitarias, fijando los porcentajes de reparto de las responsabilidades financieras en caso de imposición de sanciones por parte de la UE. En su momento, se criticó la aportación sólo parcial que esta nueva regulación suponía a la pretensión de inclusión de un pacto de estabilidad nacional en la Ley Fundamental, que garantizase no sólo la asunción de responsabilidades en caso de incumplimiento de los límites establecidos al déficit, sino sobre todo que aspirara a regular un conjunto de medidas presupuestarias en el art. 115 LFB (reparto vertical Bund-Länder y horizontal del límite de endeudamiento y sanciones internas en caso de incumplimiento) que permitieran a largo plazo el respeto del actual porcentaje del $3 \%$ fijado por la $U^{51}$.

Teniendo en cuenta estas premisas, la segunda reforma del federalismo alemán durante la década de 2010 tuvo como protagonista a la constitución financiera. El paso del tiempo había hecho evidente que el endeudamiento de la Federación y de los Länder era tan elevado que hacía imposible cumplir con las exigencias del PEC. ARROYo GIL ha señalado que si bien ello no era atribuible a la letra de la Ley Fundamental, no era menos cierto que la permisividad de algunas de sus disposiciones sobre el recurso al crédito por parte de las administraciones públicas en nada favorecía la superación de esa situación de grave riesgo para la estabilidad financiera del Estado ${ }^{52}$.

Y así, la reforma de 2009 incluye fuertes límites a la capacidad de endeudamiento de la Federación y los Länder. De acuerdo con el nuevo apartado 3 del art. 109 de la Ley Fundamental, los presupuestos de la Federación

49 Quadra-SAlcedo JANINI, T. de la, «La discrecionalidad política del ECOFIN en la aplicación del procedimiento por déficit excesivo. Reflexiones tras la Sentencia del TJCE del 13 de Julio de 2004», Revista de Estudios Políticos, núm. 126, 2004, pp. 151-176.

50 Sobre la reforma en general, ver ARroyo GiL, A., La reforma constitucional del federalismo alemán: estudio crítico de la $52^{a}$ Ley de Modificación de la Ley Fundamental de Bonn, de 28 de agosto de 2006, Intitut d'Estudis Autonòmics, Barcelona, 2009.

${ }^{51}$ Méndez, E., «La reforma de la Constitución financiera en Alemania: una reforma pendiente», Revista de Derecho Constitucional Europeo, $\mathrm{n}^{\circ}$ 6, 2006, http://www.ugr. es/ redce/.

52 Arroyo GiL, A., «La reforma constitucional de 2009 de las relaciones financieras entre la Federación y los Länder de la República Federal de Alemania», Revista d'Estudis Autonómicos i Federals, núm. 10, 2010, p. 51. 
y de los Länder, por regla general, habrán de confeccionarse excluyendo la posibilidad de acudir a ingresos procedentes de partidas crediticias. Con esta medida se pretende, en realidad, conseguir a medio plazo el objetivo de un presupuesto estructuralmente equilibrado, tal y como demanda el PEC. El propio art. 109.3 permite, de modo similar a las circunstancias excepcionales expresadas tanto en el art. 126.2 a) como en el art. 122.2 TFUE (y ahora el art. 135.4 CE), que la Federación y los Länder puedan acudir a los créditos cuando tenga lugar un desarrollo coyuntural que se aparte de la situación considerada normal o tengan lugar catástrofes naturales u otras situaciones extraordinarias de emergencia, con la condición de que se prevean los mecanismos necesarios para volver de la forma más rápida posible a una situación de equilibrio presupuestario.

El art. 109.3 de la Ley Fundamental ofrece asimismo un visión diferente del concepto de «componente estructural» del déficit si estamos ante la acción financiera de la Federación o de los Länder. Así, la prohibición de acudir al crédito en orden a la confección del presupuesto, por lo que respecta a la Federación también se cumple aun cuando existan determinados ingresos crediticios, y siempre que los mismos no superen el límite del 0,35\% del producto interior bruto nominal anual. Sin embargo, a los Länder les es vetado ese componente estructural, pues más allá de las situaciones de necesidad que requieran regulaciones excepcionales, tendrán radicalmente prohibido acudir al crédito en la confección de sus presupuestos.

Por lo que se refiere al art. 115 de la Ley Fundamental, tras reiterar el apartado segundo la previsión ya vista del art. 109.3, relativa a la prohibición general de acudir a los ingresos procedentes de créditos para equilibrar los ingresos y los gastos, se recuerda que no contradicen esta previsión aquellos ingresos crediticios (de la Federación) que no superen el 0,35\% del producto interior bruto nominal. Adicionalmente, en el supuesto de que tenga lugar un desarrollo coyuntural que se desvíe de la situación considerada normal, se habrán de tener en cuenta, con igual alcance, tanto los efectos que sobre el presupuesto puedan tener los casos de recuperación como los de recesión económica ${ }^{53}$. Asimismo, este art. 115.2 de la Ley Fundamental prevé que las desviaciones sobre los límites superiores válidamente fijados más arriba que se produzcan, de facto, en la utilización del crédito, quedarán comprendidas en una «cuenta de control»; en este sentido, los adeudos que superen el umbral del $1,5 \%$ del producto interior bruto nominal habrán de reducirse en caso de evolucionar favorablemente la coyuntura económica.

Las reformas del art. 109 y 115 de la Ley Fundamental se han aplicado, según la disposición transitoria del art. 143 d), a partir del año presupuestario 2011. Sin embargo, esta disposición transitoria permite que los Länder, durante el período comprendido entre el 1 de enero de 2011 y el 31 de di-

53 Seguimos la traducción y comentarios de Arroyo GIL, A., «La reforma constitucional de 2009 de las relaciones financieras entre la Federación y los Länder de la República Federal de Alemania», ob. cit., p. 58. 
ciembre de 2019, de conformidad con lo que disponga su normativa válidamente aprobada, puedan desviarse de las prescripciones del art. 109.3 de la Ley Fundamental (prohibición general de confeccionar los presupuestos acudiendo a ingresos procedentes de partidas crediticias). La relajación de esta prohibición constitucional en el caso de la Federación es temporalmente más limitada, ya que sólo podrá desviarse de la prescripción del art. 115.2 durante el período de tiempo comprendido entre el 1 de enero de 2011 y el 31 de diciembre de 2015, debiéndose comenzar, además, a reducir el déficit ya existente a partir del año presupuestario 2011. En ambos casos, las regulaciones de detalle, en especial, los pasos a dar anualmente para proceder a la supresión de los déficits financieros, la supervisión del desmantelamiento de los mismos por parte del recién creado Consejo de Estabilidad, así como las consecuencias que se deriven en caso de no cumplir con ese procedimiento gradual tendente a la eliminación de los referidos déficits, serán establecidas por medio de ley federal ${ }^{54}$.

Con el objeto de complementar la nueva regulación de las deudas estatales, tanto de la Federación como de los Länder, la reforma constitucional de 2009 contiene también una serie de previsiones cuyo fin no es otro que evitar la aparición de situaciones de emergencia presupuestaria. A tal efecto, el nuevo art. 109 a) de la Ley Fundamental remite a una ley federal, la regulación de la supervisión continua del régimen presupuestario de la Federación y los Länder a través de un organismo común de nueva creación, el Consejo de Estabilidad (art. 109 a), que estará integrado por los Ministros de Finanzas de la Federación y de los Länder, así como por los Ministros federales de Economía y Tecnología. Este Consejo vigilará, sobre todo, la ejecución de los presupuestos de la Federación y de los Länder, y, muy en particular, los progresos que realicen los cinco Länder receptores de ayudas a la consolidación a que se refiere el nuevo art. 143 d) de la Ley Fundamental.

\subsection{La estabilidad presupuestaria en España antes de la reforma del art. $135 \mathrm{CE}$}

Las Cortes Generales de nuestro país aprobaron en 2001 la Ley General de Estabilidad Presupuestaria y la Ley Orgánica Complementaria de la Ley General de Estabilidad Presupuestaria ${ }^{55}$, recogiéndose en esta última los aspectos de la ley relacionados específicamente con la autonomía financiera de las Comunidades Autónomas. El objetivo de ambas fue asegurar la continuidad de la política de rigor presupuestario aplicada hasta entonces, y sobre todo, cumplir con los compromisos adquiridos por España en el marco de la

${ }^{54}$ Arroyo Gil, A., «La reforma constitucional de 2009 de las relaciones financieras entre la Federación y los Länder de la República Federal de Alemania», ob. cit., p. 61.

${ }_{55}$ España. Ley 18/2001, de 12 de diciembre, General de Estabilidad Presupuestaria. Boletín Oficial del Estado, 13 de diciembre de 2001, nº 298; y Ley Orgánica 5/2001, de 13 de diciembre, complementaria a la Ley General de Estabilidad Presupuestaria. Boletín Oficial del Estado, 14 de diciembre de 2001, núm. 299. 
UE, particularmente con el PEC. Ya por entonces, se apuntaban otras razones de índole económica, no solamente presupuestaria, que se han demostrado decisivas a la hora de entender la complicada deriva que ha tomado la economía española a partir de 2007, con la explosión de la crisis financiera ${ }^{56}$.

Sea como fuere, existe consenso al señalar que las normas aprobadas en el año 2001 adoptaron una definición estricta del principio de estabilidad presupuestaria, ya que exigía que cada una de las Administraciones Públicas (Estado, Seguridad Social, Comunidades Autónomas y Ayuntamientos), registrase todos los años una situación de equilibrio o superávit ${ }^{57}$. Los incumplimientos a este principio se consideraban como situaciones claramente excepcionales, que requerían una justificación muy detallada por parte de la Administración que había incurrido en déficit de las causas que las habían originado y un plan de saneamiento financiero para corregir cualquier situación de déficit en un plazo máximo de tres años. Esta definición tenía probablemente la ventaja de la sencillez y transparencia, pero también presentaba debilidades importantes por la falta de credibilidad de un objetivo tan estricto que las propias Administraciones territoriales no compartieron y por la dificultad para hacer compatible el objetivo de estabilidad presupuestaria a medio plazo con la estabilización cíclica a corto plazo de la economía ${ }^{58}$.

La oportunidad de utilizar la política fiscal para estabilizar la economía de un Estado que ha decidido centralizar supranacionalmente los tipos de interés y los tipos de cambio es especialmente importante. Sin embargo, a pesar de que inicialmente el PEC fue concebido para asegurar a los Gobiernos una posición presupuestaria saneada para poder enfrentarse mínimamente a las exigencias derivadas del ciclo $^{59}$, en la actualidad, ello queda, si no descartado, al menos desaconsejado, tal y como se recuerda en la reciente Directiva 2011/85/UE sobre los requisitos aplicables a los marcos presupuestarios de los Estados miembros (Considerando $\left.\mathrm{n}^{\circ} 18\right)^{60}$. Sea como fuere, la visión de la política fiscal que tenía el Gobierno que llevó a las Cortes las leyes presupuestarias de 2001 coincidía con la dinámica actual, rastreable en la filosofía de la reforma constitucional alemana de 2009 y en las condiciones econó-

56 Sobre éstas, GonzÁlez-PÁramo, J.M., «El Estado y las Haciendas Territoriales frente a los retos de la estabilidad presupuestaria», Revista de Estudios Regionales, núm. 66, 2003, pp. 17-40.

57 Sebastián, M., González Calbet, L. y Pérez Quirós, G., «Estabilidad presupuestaria, equidad intergeneracional y solidaridad internacional», Hacienda Pública, Monografía, 2004, pp. 151-172.

${ }^{58}$ Para hacernos una idea, en la primera liquidación de los presupuestos elaborados de acuerdo con las nuevas normas, diez Comunidades Autónomas incumplieron el objetivo que se les había fijado y más de la mitad de las corporaciones locales presentaron déficit.

${ }^{59}$ Calmfors, L., «Fiscal Policy to Stabilise the Domestic Economy in the EMU: What Can We Learn from Monetary Policy», CESIFO Economic Studies, Vol. 49, núm. 3, 2003.

${ }^{60}$ Directiva 2011/85/UE del Consejo, de 8 de noviembre de 2011, sobre los requisitos aplicables a los marcos presupuestarios de los Estados miembros, Diario Oficial de la Unión Europea, núm. L 306, de 23 de noviembre de 2011. 
micas e institucionales impuestas a los Estados miembros con problemas relacionados con la deuda soberana, de reservar el papel contracíclico de la política fiscal a la actuación de los estabilizadores automáticos ${ }^{61}$.

Ello implicaba que las Administraciones territoriales, en un momento de extraordinaria emergencia económica provocada por el dinamismo del sector inmobiliario, tuvieran importantes limitaciones presupuestarias para poner en marcha programas públicos de multiplicación de la demanda agregada y de satisfacción de derechos y prestaciones sociales ${ }^{62}$. De este modo, coincidiendo con el cambio de Gobierno en 2004 y la importancia adquirida por las minorías territoriales en las dos últimas legislaturas, se abandonó la rigidez impuesta por las leyes aprobadas en 2001, y se aprobó una reforma de las mismas cuya mayor novedad consistía en la introducción de un nuevo mecanismo para la determinación del objetivo de estabilidad de las Administraciones públicas territoriales y sus respectivos sectores públicos, apoyado en el diálogo y la negociación. Así, el objetivo de estabilidad de cada Comunidad Autónoma se acordaría con el Ministerio de Economía y Hacienda tras una negociación bilateral, sin perjuicio de que, en última instancia, fuese a las Cortes Generales y al Gobierno a los que correspondiese adoptar las decisiones esenciales sobre la política económica, conforme a lo dispuesto en el artículo 149.1.13 de la Constitución ${ }^{63}$.

La reforma permitía a las distintas Administraciones territoriales presupuestar déficit durante algunos años, siempre que se hubiera garantizado la estabilidad presupuestaria a lo largo del ciclo y cuando se llevasen a cabo programas de inversión pública que tuviesen por objetivo elevar la productividad $^{64}$. Resulta difícil concretar o valorar si las dificultades de financiación que en la actualidad tiene España, como consecuencia del incremento del déficit, tienen su origen en los cambios realizados en las normas de estabilidad presupuestaria que acabamos de comentar. Sin embargo parece obvio que uno de los objetivos explícitos de la reforma del art. $135 \mathrm{CE}$ es someter a una mayor disciplina fiscal y presupuestaria a las Administraciones territoriales. En este sentido, la Directiva 2011/85/UE sobre los requisitos aplicables a los marcos presupuestarios de los Estados miembros antes mencionada, recuerda en su Considerando $n^{\circ} 23$ que «Las disposiciones del marco de su-

${ }^{61}$ Paradigma ya puesto en duda, a mediados de la década de 2010, por Buti, M. y VAN Der Noord, P., «Fiscal Policy in EMU: rules, discretion and political incentives», European Commission, Directorate General for Economic and Financial Affairs, Economic Papers, núm. 206, 2004.

${ }^{62}$ Maestro Buelga, G., «El vínculo presupuestario comunitario y los Derechos sociales», Revista Vasca de Administración Pública, núm. 64, 2002, p. 193 y ss.

63 España. Real Decreto Legislativo 2/2007, de 28 de diciembre, por el que se aprueba el texto refundido de la Ley General de Estabilidad Presupuestaria. Boletín Oficial del Estado, 31 de diciembre de 2007, núm. 313.

${ }^{64}$ Uxó, J., Barruso, B. y RuEda, N., «Autonomía financiera, estabilidad presupuestaria y política de gasto de las Comunidades Autónomas», Revista de Economía de Castilla La Mancha, núm. 8, 2006. 
pervisión presupuestaria establecido en el TFUE y, en particular, en el PEC, son aplicables al conjunto de las administraciones públicas, que comprenden los subsectores de la administración central, las comunidades autónomas, las corporaciones locales y las administraciones de seguridad social $\rangle^{65}$.

Siguiendo esta línea de razonamiento, la reciente sentencia del TC 134/2011 ${ }^{66}$ ha abordado la capacidad del Estado para limitar la autonomía presupuestaria de las Comunidades Autónomas, como consecuencia de las normas internas (Ley 18/2001 y la Ley Orgánica 5/2001) que desarrollan el PEC. La Comunidad Autónoma de Cataluña entendió que ambas normas vulneraban la autonomía política y financiera de la Generalitat (arts. 137 y 156.1 CE), establecían un control indebido sobre el Parlamento de Cataluña que también menoscaba la autonomía financiera de la Generalitat de la autonomía local garantizada (arts. 137 y $140 \mathrm{CE}$ ) y quebrantaban la suficiencia financiera de los entes locales (art. $142 \mathrm{CE}$ ). En la sentencia, que no es necesario detallar a fondo, el TC señala que las Comunidades Autónomas tienen libertad para establecer un plan de ingresos y gastos, es decir, el presupuesto, pero dicha libertad no se establece constitucionalmente «con carácter absoluto», señalando que la autonomía financiera de las mismas «no excluye, sin embargo, la existencia de controles, incluso específicos» por parte del Estado, precisamente con el objetivo de cumplir con las exigencias del derecho comunitario ${ }^{67}$.

\section{EL NUEVO ART. 135 CE A LA LUZ DE LA NUEVA GOBERNAN- ZA ECONÓMICA EUROPEA}

\subsection{Consideraciones generales en torno a la reforma}

Los intensos debates en torno a la rápida e inesperada reforma del art. $135 \mathrm{CE}$ se han centrado en dos cuestiones fundamentales: el procedimiento seguido para llevarlo a cabo y su contenido sustantivo. En cuanto a la primera cuestión, si la reforma se planteó como una exigencia de las instituciones europeas para que el $\mathrm{BCE}$ actuase desde aquel momento en adelante para

${ }^{65}$ En el mismo sentido, los arts. 12, 13 y 14 de la Directiva 2011/85/UE del Consejo, de 8 de noviembre de 2011, sobre los requisitos aplicables a los marcos presupuestarios de los Estados miembros, Diario Oficial de la Unión Europea, núm. L 306, de 23 de noviembre de 2011, pp. 46-47.

${ }_{66}$ STC 134/2011, de 20 de julio, FJ $8^{\circ}$.

${ }^{67}$ Esta afirmación puede insertarse en el marco de las potencialidades horizontales del art. 149.1.13 CE, que permiten al Estado mantener el control sobre aquellos aspectos esenciales de la reproducción del sistema económico; sobre el impacto de esta interpretación en el sistema de descentralización, ver CARRASCO, M., El reparto de competencias entre el Estado y las Comunidades Autónomas sobre la actividad económica, op. cit. y más recientemente, teniendo en cuenta los efectos de la crisis, Viver Pi-SunYer, C., «El impacto de la crisis económica global en el sistema de descentralización política en España», Revista d'Estudis Autonómicos i Federals, núm. 13, 2011. 
relajar las tensiones de la deuda española, parece que la urgencia y el procedimiento de lectura única utilizado en el íter parlamentario es plenamente adecuado, una vez alcanzado el consenso entre las dos fuerzas políticas más importantes del país ${ }^{68}$. A este respecto, es preciso recordar que el número de votos alcanzado en el Congreso y en el Senado supera con creces los 3/5 exigidos por el art. $167 \mathrm{CE}$ que regula el procedimiento de reforma. Resulta difícil de aceptar, en este sentido, la afirmación que señala que se ha roto el consenso constitucional en lo que respecta a los nacionalismos periféricos, cuando las enmiendas más importantes planteadas desde el País Vasco y Cataluña nada o poco tenían que ver con el objetivo perseguido por la reforma ${ }^{69}$.

Los cambios en el art. 135 CE plantean sin embargo más problemas desde el punto de vista sustantivo. Se han señalado a este respecto varias cuestiones. La más importante, la que reclama prudencia y sagacidad a la hora de introducir reformas constitucionales, pues cuando se decide elevar al máximo rango normativo un determinado precepto, ha de estar justificado que se trata de materias propias de una Constitución, para que no se produzcan efectos indeseados desde el punto de vista de la coherencia y la unidad del ordenamiento jurídico ${ }^{70}$. En este sentido, la introducción en el art. $135 \mathrm{CE}$ de principios y reglas que traen causa directa de normas comunitarias, puede producir tensiones interpretativas por la sencilla razón de que ninguna otra norma de la constitución económica ha sido convenientemente adecuada a las exigencias particulares o generales del derecho comunitario ${ }^{71}$.

Se ha apuntado, también, que la reforma no constituye un ataque al Estado del bienestar. Ello porque el principio de equilibrio presupuestario solo

${ }^{68}$ Es cierto que el objeto y la importancia de la reforma constitucional no parecen cohonestar con los requisitos establecidos por las normas reglamentarias para la utilización de la lectura única («la naturaleza del proyecto o proposición de ley» o cuando «su simplicidad de formulación lo permita»). Sin embargo, la práctica parlamentaria enseña que el factor clave para la fijación del supuesto de hecho del procedimiento de lectura única lo constituye la existencia de consenso político suficiente para lograr el beneplácito de la Cámara, no los supuestos materiales; al respecto, ver Gómez LuGO, Y., «La tramitación legislativa en lectura única», InDret, núm. 4, 2007, texto que puede encontrarse en el servidor http://www.indret.com/pdf/470_es.pdf

${ }^{69}$ En un caso, el reconocimiento del derecho de autodeterminación; en otro, la introducción de límites a la solidaridad financiera interregional; al respecto, ver TAJADURA TEJADA, J., «Reforma constitucional e integración europea», ob. cit., p. 27.

70 Blanco Valdés, R., «La reforma de 2011: de las musas al teatro», Claves de razón práctica, núm. 216, 2011.

${ }^{71}$ En este sentido se ha señalado que la privatización de los servicios públicos y la tecnificación de los instrumentos de dirección económica provocada por el proceso de integración y su variedad institucional, obliga a buscar nuevos mecanismos y fórmulas que puedan satisfacer con eficacia la necesidad de control democrático de los poderes públicos. Albertí Rovira, E., «La constitución económica de 1978 (Reflexiones sobre la proyección de la Constitución sobre la economía en el XXVV Aniversario de la Constitución española)», Revista Española de Derecho Constitucional, núm. 71, 2004, en especial el epígrafe núm. 3. 
induciría a la conformación de un nuevo consenso sobre las necesidades y por lo tanto sobre la estructura de gasto de nuestras sociedades. Sobre este tema hay un a priori erróneo que es necesario refutar: el endeudamiento y el déficit estructural no sirven únicamente para financiar el Estado del bienestar, sino para intentar adecuarse al ciclo y concretar fórmulas de crecimiento económico. Es el crecimiento el que genera el empleo, la riqueza y los recursos que son detraídos del mercado para financiar las políticas sociales. Por tanto, el art. $135 \mathrm{CE}$ perfila una nueva economía no financiarizada, de cuyo desenvolvimiento dará cuenta el futuro, pero que en todo caso está destinada a funcionar bien en economías altamente competitivas, con una balanza de pagos saneada y no dependientes del consumo interno, como es el ejemplo de los países nórdicos y Alemania ${ }^{72}$.

Hay una última cuestión que nos gustaría señalar. Más allá de la necesidades políticas o coyunturales, no parece conveniente integrar en la Constitución aspectos del derecho comunitario material a modo de reglas y normas específicas. Ello aunque lo haya hecho previamente Alemania. La primacía del derecho comunitario, con la única salvedad de los contralímites ya establecidos por nuestro Alto Tribunal en el Dictamen $1 / 2004^{73}$, es de obligado cumplimiento para los poderes nacionales, que tienen que poner todos los medios jurídicos necesarios para hacerlo efectivo. La inconveniencia de concretizar con perfiles reglamentarios derecho comunitario es doble. Por un lado, por el dinamismo que ha mostrado éste último desde su aparición, tanto en el plano originario como derivado, lo que puede convertir al derecho constitucional nacional en anacrónico o simplemente erróneo, como ocurre con el art. 135.3 CE, donde se hace referencia a los valores de referencia de deuda del TFUE, cuando estos se encuentran en el Protocolo $n^{\circ} 12$ sobre el procedimiento aplicable al déficit excesivo.

Por otro lado, la necesidad de desarrollar el principio de estabilidad presupuestaria, revela un problema relacional con la norma originaria que debe inspirar la ley orgánica que haya de desplegar el art. $135 \mathrm{CE}$. El parámetro concreto de la ley será la Constitución, el TFUE, el tratado que regulará la nueva unión fiscal y la ingente cantidad de normas derivadas (principalmente reglamentos) que desarrollan el PEC. Dado el curso de los acontecimientos, y los numerosos cambios que sobre la cuestión están teniendo lugar, no es

${ }^{72}$ Sobre los perfiles de la economía financiarizada que ha conducido a la crisis, ver Aglietta, M. y Barrebi, L., Désordres dans le capitalisme mundial, Odile Jacob, París, 2007; SACHs, J., Economía para un planeta abarrotado, Mondadori, Barcelona, 2008; o SEN, A., «Capitalism beyond the crisis», The New York Review of Books, Vol. 56, núm. $5,2009$.

73 Sobre ésta, ver VV.AA., Constitución española y Constitución europea. Análisis de la Declaración del Tribunal Constitucional (DTC 1/2004, de 13 de diciembre), Centro de Estudios Políticos y Constitucionales, Madrid, 2005. 
descartable que el legislador español se encuentre con contenidos cuando menos dispares en las normas anteriormente mencionadas ${ }^{74}$.

\subsection{El principio de estabilidad dentro de un presupuesto europeizado}

El art. 135 CE deberá interpretarse dentro de las nuevas condiciones de gobernanza económica que ha aprobado la UE en noviembre de 2011. Nos referimos al conjunto de normas aprobadas mayormente mediante el procedimiento de codecisión, que conforman lo que se ha venido a denominar como «nueva gobernanza económica europea» Dentro de estas normas, destaca en primer lugar Directiva 2011/85/UE del Consejo, sobre los requisitos aplicables a los marcos presupuestarios de los Estados miembros.

La Directiva establece el principio básico de ajuste de los ciclos presupuestarios nacionales a las exigencias procesales y sustantivas del PEC (art. 1). Ello se traduce en tres cambios fundamentales. En primer lugar, el proceso presupuestario nacional tiene que estar enmarcado por unas «reglas fiscales numéricas» de carácter plurianual (art. 3) que fijen los parámetros fiscales dentro de los cuales ha de elaborarse cada ley de presupuestos. Tales reglas fiscales tendrán que tasar los supuestos excepcionales en que los topes fijados en las mismas no sean de aplicación, pero también las consecuencias concretas y específicas de su incumplimiento (Art. 6). En segundo lugar, cada marco presupuestario plurianual ha de elaborarse en torno al Marco Presupuestario a Medio Plazo (arts. 9 y 10), que se extiende al año corriente y los tres sucesivos, y que sólo ha de ser revisado al final del ciclo de cuatro años. Las cifras que contenga este nuevo instrumento, que hasta ahora era el eje sobre el que se había de vertebrar el Programa de Estabilidad o Convergencia nacional, pasan a ser la espina dorsal del proceso presupuestario interno de todos los Estados miembros.

En tercer y en último lugar, el Marco Presupuestario a Medio Plazo nacional habrá de fijar un objetivo de déficit, pero también uno de deuda. Y para ello dará cuenta de las principales partidas de ingresos y gastos, con especificación de los niveles de gobierno en los que se producirán, así como de las principales políticas fiscales y su impacto en la sostenibilidad a largo plazo de las finanzas públicas. De ello se deriva que el procedimiento presupuestario nacional tendrá un carácter plurianual, en lugar del tradicional y clásico anual. La Directiva es explícita al afirmar que tanto las reglas fiscales como el Marco Presupuestario a Medio Plazo limitan la discrecionalidad del legislador al elaborar el presupuesto anual (art. 10). Ello implica un cambio importante, al trasladar el centro de gravedad desde la ley de presupuestos,

${ }^{74}$ Por ejemplo, la excepción del art. 135.4 CE, que señala que los límites de déficit estructural y de volumen de deuda pública sólo podrán superarse en «situaciones de emergencia extraordinaria que escapen al control del Estado y perjudiquen considerablemente la situación financiera o la sostenibilidad económica o social del Estado», no se encuentra directamente reconocida en el derecho comunitario. 
tal y como hace el art. $134 \mathrm{CE}$, a las normas que fijan un marco presupuestario mucho más amplio.

La Directiva 2011/85/UE también limita la libertad de configuración de las relaciones entre gobierno central y gobiernos regionales y locales, trascendiendo la tradicional autonomía institucional de los Estados Miembros (art. 4 TUE), al exigir que se establezcan mecanismos de coordinación fiscal entre los distintos niveles de gobierno y cauces procedimentales que aseguren que el sector público paraestatal no elude el marco presupuestario. Así se señala explícitamente en el Capítulo IV de la Directiva, donde se regula la transparencia de las finanzas de las administraciones públicas y el ámbito de aplicación global de los marcos presupuestarios ${ }^{75}$.

La europeización del presupuesto nacional queda asegurada porque el Marco Presupuestario a Medio Plazo se enclava en el «Semestre Europeo», instrumento creado por el Reglamento (UE) N $\mathrm{N}^{\mathrm{0}}$ 1175/2011 del Parlamento Europeo y el Consejo, de 16 de noviembre de 2011, por el que se modifica el Reglamento (CE) $n^{\circ} 1466 / 97$, relativo al refuerzo de la supervisión de las situaciones presupuestarias y a la supervisión y coordinación de las políticas económicas.

El Semestre Europeo (art. 2 bis) arranca en enero con la fijación de pautas supranacionales (las orientaciones generales de política económica y las orientaciones de política de empleo), prosigue con la presentación de los programas nacionales de estabilidad y convergencia, continúa con la evaluación por parte de la Comisión y del Consejo, atendiendo a criterios macroeconómicos, de estabilidad presupuestaria y de crecimiento económico y concluye con la vigilancia de la ejecución de los planes de estabilidad y convergencia (donde se incluyen los marcos presupuestarios anuales y plurianuales de los Estados). Este nuevo instrumento refuerza la coordinación de las políticas fiscales y de manejo macroeconómico en manos de los Estados Miembros, convirtiendo la coordinación en un ejercicio de vigilancia preventiva. Y ello no solo porque el Semestre Europeo antecede al proceso presupuestario nacional, sino porque los programas de estabilidad y convergencia se convierten en antecedente necesario del presupuesto nacional (art. 4), debiendo el procedimiento presupuestario nacional iniciarse habiendo ya

${ }^{75}$ Como ya señalábamos páginas atrás, el Considerando núm. 23 de la Directiva establece que «Las disposiciones del marco de supervisión presupuestaria establecido en el TFUE y, en particular, en el PEC, son aplicables al conjunto de las administraciones públicas, que comprenden los subsectores de la administración central, las comunidades autónomas, las corporaciones locales y las administraciones de seguridad social». 
sometido la propuesta que el Gobierno lleve ante las Cortes a la opinión de Comisión y Consejo ${ }^{76}$.

\subsection{Disciplina fiscal y control del endeudamiento: del art. $135 \mathrm{CE}$ al derecho comunitario}

La constitución económica europea impone fundamentalmente control y disciplina sobre los Estados miembros. Se ha entendido que los problemas que presenta el gobierno de la economía en el sistema constitucional multinivel no tienen que ver con la indeterminación institucional, sino con el incumplimiento de los niveles relativos a los estabilizadores automáticos incluidos en el PEC. Independientemente de que ello pueda ser considerado un error ${ }^{77}$, lo importante en estos momentos es interpretar las posibles consecuencias de las reglas concretas del art. $135 \mathrm{CE}$, teniendo en cuenta el derecho comunitario surgido tras las reformas que venimos citando.

Quizá el elemento más importante del nuevo art. $135 \mathrm{CE}$ es el concepto de «déficit estructural» que contiene su apartado segundo ${ }^{78}$. De su interpretación dependerá que los instrumentos fiscales a nivel nacional sigan teniendo un cierto valor contracíclico, tal y como se pretendió en la reforma de las leyes presupuestarias en España en el año 2007, o que se configuren como simples estabilizadores automáticos, de acuerdo a la filosofía que inspiró su elaboración en el año 2001. En el ámbito de la coordinación y la supervisión europea, parecería que la reforma de noviembre de 2011 se inclina por la primera opción, aunque como veremos en el siguiente apartado, los férreos mecanismos de vigilancia y sanción y el nuevo papel que adquirirán las ins-

${ }^{76}$ Así, el art. 3.4 del nuevo Reglamento antes citado, señala que «Cada uno de los programas [de estabilidad] contendrá información sobre su estado en el contexto de los procedimientos nacionales, en particular sobre si se ha presentado al Parlamento nacional y sobre si el Parlamento nacional ha tenido oportunidad de examinar el dictamen del Consejo sobre el programa anterior y, en su caso, toda recomendación o advertencia al respecto, y sobre si el programa ha recibido aprobación parlamentaria».

77 El economista Paul De Grauwe ha demostrado, con singular agudeza, el error de todo el complejo de reformas iniciado tras la quiebra de Grecia: con la excepción de este país, la mayor parte de los Estados miembros de la zona euro habían tenido un comportamiento fiscal aceptable en el marco de las referencias y parámetros establecidos por el PEC hasta el 2007. Es en el momento en el que los gobiernos tienen que hacer frente a los fallos financieros del sector privado, en el que los ratios de la deuda pública y el déficit se disparan. Por ello, no ha habido tanto un problema de regulación y disciplina, como de falta absoluta de dirección política de la economía, tanto a nivel nacional como comunitario. Grauwe, P. de, «Fighting the wrong enemy», VOX. Research - based policy analysis and commentary from leading economist, 19 de mayo de 2010, http://www.voxeu.org

${ }^{78}$ El déficit estructural es aquél que no incluye los gastos y los ingresos vinculados a las expansiones y a las recesiones del ciclo económico. A título de ejemplo, y según cálculos efectuados por la Comisión Europea, en 2010 el déficit absoluto de España alcanzó el $9,2 \%$ del PIB, pero su déficit estructural fue del 7\% del PIB. De igual modo, el superávit absoluto del 2006 fue del 2\% del PIB, mientras que el superávit estructural sólo alcanzó el $1,5 \%$ del PIB. 
tituciones supranacionales (particularmente la Comisión y el BCE), hacen pensar en que la UE apuesta claramente por dar un papel autónomo a los estabilizadores fiscales automáticos dentro del PEC.

Como ya ocurría antes de la reforma, el equilibrio presupuestario se identifica con la consecución del objetivo presupuestario a medio plazo. En el caso de que ese objetivo no haya sido alcanzado aún, el PEC exige que los Estados sigan una trayectoria de ajuste presupuestario que asegure la consecución de ese objetivo. La principal novedad resultante de la reforma es la profundización del concepto de trayectoria de ajuste, de modo que el mismo pierde en buena medida su condición de «principio» y se asemeja ahora a una «regla» de aplicación cuasi-automática. Se afirma así que el objetivo presupuestario a medio plazo tiene que ser tal que permita mantener siempre y en toda circunstancia un margen de seguridad suficiente respecto al valor de referencia en materia de déficit ( $3 \%$ del PIB), de modo que nunca se supere ese valor, incluso cuando haya de hacerse uso de la política presupuestaria contra cíclica para el manejo macroeconómico. De ahí que en términos operativos, el déficit anual no haya de ser superior al 1\% del PIB. Este objetivo, como era ya el caso desde la reforma de 2005, se fija sin embargo de forma individualizada para cada Estado miembro.

Al criterio introducido en 2005, codificando los criterios desarrollados en la práctica presupuestaria del PEC, por el que se obligaba a una mejora de al menos un $0.5 \%$ del PIB anual en la posición presupuestaria, se une ahora la regla según la cual el nivel de crecimiento del gasto público no ha de superar el potencial de crecimiento a medio plazo de la economía nacional. Por ello, el Consejo y la Comisión, al evaluar la trayectoria de ajuste a partir de la cifra antes citada, deberán examinar si el Estado miembro de que se trate persigue la mejora anual apropiada de su saldo presupuestario en función del ciclo, una vez excluidas las medidas puntuales y otras medidas de carácter temporal ${ }^{79}$.

El art. 135.3 CE señala, por otro lado, que «el volumen de deuda pública del conjunto de las Administraciones Públicas en relación con el producto interior bruto del Estado no podrá superar el valor de referencia establecido en el TFUE». Independientemente de la inexactitud provocada por la alusión al TFUE, antes aludida, es importante señalar que la deuda se reafirma como criterio macroeconómico fundamental del PEC, cuestión que tendrá que ser tenida en cuenta por la futura ley orgánica que desarrolle la norma que venimos citando. El Considerando $\mathrm{n}^{\circ} 12$ del nuevo Reglamento (UE) $\mathrm{N}^{\mathrm{o}} 1177 / 2011$, relativo a la aceleración y clarificación del procedimiento de déficit excesivo, confirma que el concepto de deuda relevante es aquel que

79 Art. 5.1 del Reglamento (UE) No 1175/2011 del Parlamento Europeo y del Consejo, de 16 de noviembre de 2011, por el que se modifica el Reglamento (CE) no 1466/97 del Consejo, relativo al reforzamiento de la supervisión de las situaciones presupuestarias y a la supervisión y coordinación de las políticas económicas, Diario Oficial de la Unión Europea, núm. L 306, de 23 de noviembre de 2011, pp. 17-18. 
permite determinar la sostenibilidad «global» del gasto público. Es por ello que la Comisión, a la hora de determinar el nivel de endeudamiento de un país, tendrá que considerar el pasivo de cada Estado y su composición desde un punto de vista interno y externo, teniendo en cuenta elementos de distinta naturaleza ${ }^{80}$. La deuda es relevante en el brazo preventivo del PEC en tanto que factor determinante del esfuerzo de ajuste que han de hacer los Estados que no hayan alcanzado aún su objetivo presupuestario a medio plazo ${ }^{81}$.

En lo que concierne al brazo corrector del PEC, la deuda adquiere también una importancia autónoma en tanto que la superación del nivel de referencia (o el riesgo de que el Estado pueda asumir o haya ya asumido niveles insostenibles de deuda) puede dar lugar a la apertura de un procedimiento de déficit excesivo o por desequilibrio presupuestario. Tras la reforma se fija además una trayectoria de reducción de la deuda, al exigirse que los Estados cuya deuda sea superior al $60 \%$ del PIB reduzcan la misma en una cuantía anual equivalente a 1/20 del exceso ${ }^{82}$. En todo caso, el requisito correspon-

${ }^{80}$ Desde un punto de vista interno, el art. 2.3 c) del Reglamento (UE) No 1177/2011 del Consejo, de 8 de noviembre de 2011, por el que se modifica el Reglamento (CE) $\mathrm{n}^{\mathrm{o}}$ $1467 / 97$, relativo a la aceleración y clarificación del procedimiento de déficit excesivo, Diario Oficial de la Unión Europea, núm. L 306, de 23 de noviembre de 2011, pp. 35-36, señala que la Comisión tendrá en cuenta «la evolución de la situación de la deuda pública a medio plazo, así como su dinámica y sostenibilidad, incluidos, en particular, los factores de riesgo, incluida la estructura de vencimiento de la deuda y las monedas en que esté denominada, el ajuste entre flujos y fondos y su composición, las reservas acumuladas y otros activos financieros; las garantías, especialmente las ligadas al sector financiero, y todos los pasivos implícitos relacionados con el envejecimiento de la población, y la deuda privada, en la medida en que pueda representar un pasivo implícito contingente para el sector público». Desde un punto de vista externo, la misma disposición señala que se tendrá en cuenta la debida consideración a cualquier otro factor que, en opinión del Estado miembro de que se trate, sea pertinente para evaluar globalmente la observancia de los criterios en materia de déficit y deuda y que el Estado miembro haya puesto en conocimiento del Consejo y de la Comisión. En ese contexto, deberá prestarse particular atención a lo siguiente: las contribuciones financieras dirigidas a reforzar la solidaridad internacional y a alcanzar los objetivos de las políticas de la UE, la deuda generada en forma de apoyo bilateral o multilateral entre Estados miembros en el contexto de la salvaguardia de la estabilidad financiera, y la deuda relacionada con las operaciones de estabilización financiera durante las perturbaciones financieras importantes.

${ }^{81}$ Art. 5.1 del Reglamento (UE) 1175/2011: «Respecto de los Estados miembros que se enfrenten a un nivel de deuda que supere el $60 \%$ del PIB o a un riesgo acusado respecto a la sostenibilidad global de su deuda, el Consejo y la Comisión examinarán si la mejora anual del saldo presupuestario ajustado al ciclo, una vez descontadas las medidas puntuales y otras medidas de carácter temporal, es superior al 0,5\% del PIB».

${ }_{82}$ Art. 2.1 bis del Reglamento (UE) N 1177/2011: «Si rebasa el valor de referencia, se considerará que la proporción entre la deuda pública y el producto interior bruto (PIB) disminuye de manera suficiente y se aproxima a un ritmo satisfactorio al valor de referencia, de conformidad con el artículo 126, apartado 2, letra b), del TFUE, en caso de que la diferencia con respecto al valor de referencia haya disminuido en los tres años anteriores a un ritmo medio de una veinteava parte al año como referencia, sobre la base de los cambios registrados durante los últimos tres años respecto de los que se dispone de datos». 
diente al criterio de la deuda también se considerará cumplido si las previsiones presupuestarias de la Comisión indican que la reducción exigida del diferencial se producirá en el período de tres años que comprende los dos años siguientes al último año respecto del cual se dispone de datos.

El art. 135.4 CE señala por último que «los límites de déficit estructural y de volumen de deuda pública sólo podrán superarse en caso de catástrofes naturales, recesión económica o situaciones de emergencia extraordinaria que escapen al control del Estado y perjudiquen considerablemente la situación financiera o la sostenibilidad económica o social del Estado, apreciadas por la mayoría absoluta de los miembros del Congreso de los Diputados». En esta línea, el PEC establece nuevas cláusulas de escape o "circunstancias económicas excepcionales», que permiten desviaciones temporales de la trayectoria de ajuste hacia el objetivo presupuestario a medio plazo. Se habla, por tanto, de desviaciones en el objetivo presupuestario a medio plazo, no de la superación de los límites de déficit estructural y de deuda pública, que podrían comportar volúmenes distintos, de acuerdo a lo que venimos señalando. Así, a la cláusula individual, definida en el art. 126.2 a) TFUE, se unen otros dos supuestos. El primero se inspira de forma evidente en el artículo 122.2 TFUE, al establecer que un «acontecimiento inusitado sobre el que el Estado miembro afectado no tenga ningún control y que tenga efectos considerables sobre la situación de su hacienda pública» justifica una separación temporal de la trayectoria de ajuste presupuestario o de evolución de la deuda pública ${ }^{83}$. Tiene, al igual que la cláusula «tradicional» del PEC, el carácter de «excepción» individual, en tanto que el presupuesto de hecho de la misma es una situación que afecta aisladamente a un Estado de la UE. El segundo, por el contrario, tiene un marcado carácter colectivo (al contrario que lo establecido por el art. 135.4 CE), al definirse mediante referencia a «crisis económica grave en la zona del euro o en el conjunto de la Unión Europea» (Artículo 5.1 del Reglamento (UE) No 1177/2011).

El error del art. 135.4 CE no se limita a la consideración de una excepción de carácter individual (recesión económica) que en el derecho comunitario tiene naturaleza colectiva, sino en el sujeto a quien corresponde la apreciación del supuesto de hecho que avale la «cláusula de escape» en lo relativo al incumplimiento del PEC. En nuestra opinión ello no puede corresponder a las Cortes Generales por mayoría absoluta, sino al Consejo y la Comisión, en el marco de la coordinación y supervisión supranacional de las políticas económicas y presupuestarias que establecen los Reglamentos (CE) 1466/97 y 1467/97. Los Estados miembros tienen la obligación de cumplir con el derecho de la UE, pero a las autoridades comunitarias la función de controlar y sancionar que esa obligación se haya hecho efectiva. La contradicción es más patente, en la medida en que el tratado de estabilidad, coordinación y

${ }^{83}$ Una exégesis de dicho artículo, a raíz de la crisis, en Louis, J.V., «Guest editorial: the non-bailout clause and rescue packages», Common Market Law Review, Vol. 47, núm. 4, 2010, pp. 971- 986. 
gobernanza, otorga competencias al TJUE sobre la coordinación, supervisión $\mathrm{y}$ vigilancia de las normas derivadas del PEC.

\subsection{Vigilancia y sanción en el marco del principio de estabilidad presu- puestaria: el «nuevo» procedimiento de déficit excesivo}

Resulta evidente que la eficacia del principio de estabilidad presupuestaria y de las normas que regulan el PEC, depende en buena medida de la capacidad de control sobre el gasto que se produce en el balance entre las diferentes Administraciones, no solamente territoriales, que hay en el Estado. Ya hemos visto que esta es una cuestión que preocupa especialmente a la UE, razón por la cual la Directiva 2011/85/UE conminaba a los Estados a velar por que el alcance de las obligaciones y procedimientos establecidos en los marcos presupuestarios nacionales se extienda debidamente a todos los subsectores de las Administraciones públicas (Considerando $\left.\mathrm{n}^{\circ} 24\right)$. En este sentido, es importante recordar que las reformas alemanas sobre la cuestión, desde el año 2006, han puesto especial atención a la forma en que se repartirán las cargas por incumplimiento de los parámetros del PEC y a los órganos que corresponderá la supervisión del régimen presupuestario en todos los niveles políticos.

Así, el art. 135.5 CE señala que la futura ley orgánica desarrollará la participación, en los procedimientos respectivos, de los órganos de coordinación institucional entre las Administraciones públicas en materia de política fiscal y financiera, regulando la distribución de los límites de déficit y de deuda entre las distintas Administraciones, la metodología y el procedimiento para el cálculo del déficit estructural y la responsabilidad de cada nivel político en caso de incumplimiento de los objetivos de estabilidad presupuestaria. Las opciones aquí son diversas: recurrir a un órgano político, como ha hecho Alemania (Consejo de Estabilidad) en el que participen los distintos responsables en materia financiera del Estado, las Comunidades Autónomas y las Administraciones Locales, o constituir una autoridad central e independiente a la que se le encomiende la supervisión de todos los presupuestos de una manera técnica ${ }^{84}$. En tal caso, serían expertos los que desde un punto de vista no partidista estudiarían las condiciones de las cuentas públicas y el efecto del ciclo económico sobre las mismas ${ }^{85}$.

Sin embargo, el mayor problema vendrá de la capacidad de ejecución de los controles y las sanciones, dentro de un Estado descentralizado en el que la Administración central no cuenta siempre con instrumentos directos para hacer aplicar de manera efectiva las políticas económicas y financieras, como

${ }^{84}$ Como postula Tajadura TejadA, J., «Reforma constitucional e integración europea», ob. cit., p. 24.

${ }^{85}$ Fernández -Villaverde, J., «Las reglas fiscales y la Constitución», El País, 26 de agosto de 2011 . 
es lo propio en el federalismo de ejecución ${ }^{86}$. La nueva Ley Orgánica de estabilidad presupuestaria ha tenido en cuenta esta realidad, y tomando como referencia el art. $155 \mathrm{CE}^{87}$, ha establecido una regulación que en cierta forma considera que el incumplimiento del principio de estabilidad presupuestaria, es un doble incumplimiento de las obligaciones constitucionales: las que directamente impone el art. $135 \mathrm{CE}$ y las que indirectamente se derivan del art. $93 \mathrm{CE}^{88}$. La importancia de este hecho de deriva no solamente desde un punto de vista formal (observancia de las exigencias derivadas del ordenamiento jurídico), sino propiamente material, que no es otro que el exigente régimen de multas que la UE ha establecido en el marco del PEC y de la estabilidad macroeconómica ${ }^{89}$.

Por ello conviene hacer una breve alusión a las nuevas circunstancias que conlleva la apertura de un proceso sancionador en el marco del PEC, que sin duda revelan una mayor centralización del gobierno de la economía en términos supranacionales, lo que obliga a poner una mayor atención en el cumplimiento del derecho comunitario en la cuestión. Así, una vez que los desequilibrios presupuestarios o el crecimiento de la deuda conducen a que un Estado supere los valores de referencia (3\% del PIB de déficit anual, $60 \%$ del PIB de deuda), la Comisión ha de elaborar un informe para determinar si ha de iniciarse o no un procedimiento de déficit excesivo. La discrecionalidad de la Comisión queda claramente enmarcada en la medida en la que no sólo se enumeran de forma expresa los criterios que ha de considerar la Comisión relevantes a la hora de determinar la existencia de desequilibrios macroeconómicos, sino que se excluye que los mismos puedan llevar a concluir que no haya de abrirse un procedimiento de déficit excesivo si el Estado supera el valor de referencia del $60 \%$ de la deuda pública.

Tras la publicación del Informe de la Comisión y antes de que se produzca un debate ante el Parlamento Europeo, el Consejo dispone entonces

${ }^{86}$ Algunas de estas cuestiones se dejan translucir en Cazorla Prieto, L.M., Crisis económica y transformación del Estado, Aranzadi, Pamplona, 2009.

${ }^{87}$ Sobre la actualidad y posibilidades de aplicación del art. 155 CE, ver VIRGALA FoRURIA, E., «La coacción estatal del artículo 155 de la Constitución», Revista Española de Derecho Constitucional, núm. 73, 2005.

${ }^{88}$ Como ya sabemos, nuestro TC no ha llegado a considerar inconstitucionales las normas internas que impiden o comprometen el respeto a los Tratados comunitarios. Sobre esta cuestión, ver Miguel Bárcena, J. de, «España», en TAJAdura Tejada, J. y Miguel BÁrcena, J. de (coords.), Justicia constitucional y Unión Europea, Centro de Estudios Políticos y Constitucionales, Madrid, 2008, p. 145 y ss.

${ }^{89}$ Asunto que no ha sido tratado aquí, pero sobre el que versan los recientes Reglamento (UE) No 1176/2011 del Parlamento Europeo y el Consejo, de 16 de noviembre de 2011, relativo a la prevención y corrección de los desequilibrios macroeconómicos, Diario Oficial de la Unión Europea, núm. L 306, de 23 de noviembre de 2011; y Reglamento (UE) $\mathrm{N}^{\mathrm{o}}$ 1174/2011 del Parlamento Europeo y del Consejo, de 16 de noviembre de 2011, relativo a las medidas de ejecución destinadas a corregir los desequilibrios macroeconómicos excesivos en la zona del euro, Diario Oficial de la Unión Europea, núm. L 306, de 23 de noviembre de 2011. 
de cuatro meses (tres si la situación es muy grave) para decidir por mayoría cualificada la aprobación de una decisión en la que se establezca la existencia de un déficit excesivo y se inste al Estado miembro que incurre en tal circunstancia a adoptar las medidas pertinentes en un plazo de seis meses, de modo que haya podido corregir el déficit excesivo en el plazo de un año. La principal novedad en este estadio del procedimiento consiste en la previsión de que si son los Estados de la zona euro los destinatarios de una recomendación que establezca la existencia de un déficit excesivo, el Consejo deberá decidir por mayoría cualificada inversa la constitución de un depósito sin intereses ${ }^{90}$. La cantidad de dicho depósito se corresponde con el 0,2\% del PIB nacional, que en el caso de España serían aproximadamente 2900 millones de $€$. La mayoría cualificada inversa significa que la propuesta de la Comisión se tendrá por aprobada si una mayoría cualificada de Estados no se opone a la misma, lo que complica mucho la consecución de alianzas que evite la sanción en el seno del Consejo, porque los Estados miembros incursos en el procedimiento de sanción tienen excluido su derecho de voto ${ }^{91}$.

\section{CONCLUSIONES}

El presente trabajo ha pretendido realizar un análisis de la reciente reforma del art. $135 \mathrm{CE}$, tomando en consideración las exigencias del derecho comunitario y de la gobernanza económica europea. Frente a la idea extendida de que el contenido sustantivo del nuevo art. $135 \mathrm{CE}$ podrá ser eludido mediante la interpretación flexible de la ley orgánica de desarrollo, aquí se ha mantenido que los instrumentos de gobierno económico de los Estados miembros (entre ellos la política presupuestaria y el régimen fiscal) se verán sometidos cada vez más a la disciplina y el control de las instituciones comunitarias. Si en los últimos años ello no ha sido así, se ha debido a que algunos gobiernos nacionales han incumplido las obligaciones derivadas del derecho realizado en el contexto de la constitución económica europea, como consecuencia de prácticas estadísticas fraudulentas (Grecia) o de políticas económicas especialmente frágiles frente a los periodos de inestabilidad financiera como el que se ha producido durante la actual crisis (España, Italia, Portugal o Irlanda).

En este sentido, se ha recordado la importancia de recuperar -las circunstancias así lo imponen- el concepto de constitución económica. El art. $135 \mathrm{CE}$ se encuentra ubicado en el Título referido a la Economía y Hacienda,

${ }^{90}$ Art. 5 del Reglamento (UE) N N $^{\mathrm{O}} 1173 / 2011$ del Parlamento Europeo y del Consejo, de 16 de noviembre de 2011, sobre la ejecución efectiva de la supervisión presupuestaria en la zona del euro, Diario Oficial de la Unión Europea, núm. L 306, de 23 de noviembre de 2011, p. 4.

${ }_{91}$ Art. 5 del Reglamento (UE) No1174/2011 del Parlamento Europeo y del Consejo, de 16 de noviembre de 2011, relativo a las medidas de ejecución destinadas a corregir los desequilibrios macroeconómicos excesivos en la zona del euro, Diario Oficial de la Unión Europea, núm. L 306, de 23 de noviembre de 2011, p. 10. 
cuyas disposiciones, particularmente las referidas a la planificación económica, los servicios públicos o la estructura impositiva del Estado, ya habían sido reconstruidas de acuerdo a los perfiles reguladores que caracterizan el derecho comunitario sobre la materia. Sin embargo, lo novedoso de la reciente reforma constitucional es que por primera vez incorpora formalmente aspectos relacionados con la política presupuestaria que prescriben los Tratados y el derecho derivado de la UE. Ello supone una relajación de las tensiones producidas por la absorción competencial que la constitución económica europea lleva produciendo desde hace décadas, aunque su contenido pueda resultar discutible desde el punto de vista de la afirmación de modelos económicos constitucionalmente distintos.

El sistema competencial de la UE ha sido especialmente proclive a la afirmación de una constitución económica integrada, no solo en el ámbito de la construcción de un mercado único. Por ello, la coordinación de las políticas económicas que establece el art. 5 TFUE, dentro del nuevo catálogo competencial introducido por el Tratado de Lisboa, debe ser interpretado como un título horizontal en el que los objetivos prescritos en el art. 3 TUE encuentran un mecanismo ideal para que la gobernanza económica europea pueda anclarse, no sin dificultades, en los distintos sectores del derecho material nacional, como ha demostrado la reciente trasposición de la Directiva relativa a los servicios en el mercado interior. El paralelismo con los desarrollos históricos de otras experiencias federales (Estados Unidos y Alemania) es más que evidente, aunque la UE tiene una particularidad al respecto: al margen de la importancia de los ámbitos competenciales exclusivos y derivativos, todo el esquema competencial comunitario presenta los perfiles de una concurrencia práctica (art. 2.2 TFUE), lo que permite que las decisiones políticas en el seno de las instituciones comunitarias, puedan desplazar con cierta facilidad las competencias estatales, como ha sido el caso de las concernientes al gobierno de la economía.

La incorporación en este ámbito, del Pacto de Estabilidad y Crecimiento, impone la concepción de una nueva política fiscal y presupuestaria en la que la economía pretende ser controlada jurídicamente mediante la imposición de unos estabilizadores automáticos. Los Estados miembros han tenido dificultad para incorporar e interpretar los parámetros que impone el derecho comunitario sobre la cuestión, probablemente porque la fiscalidad y la ley de presupuestos son los únicos instrumentos, una vez cedida la moneda a la UE, que permanecen formalmente en manos de las autoridades nacionales para realizar una política económica diferenciada dentro de la coordinación general europea. Por ello, algunos países, entre ellos Alemania, han reformado sus Constituciones con el objetivo de imponer una mayor disciplina a las instituciones internas, lo que implica a su vez una mejora de la articulación de responsabilidades financieras entre los diferentes niveles administrativos y de gobierno. La reforma del art. $135 \mathrm{CE}$, que guarda un evidente paralelismo con lo establecido en el Título X de la Ley Fundamental alemana, ha 
venido sin embargo impuesta por unas exigencias económicas internacionales que rozan el dramatismo. La gravedad de la crisis financiera (y por ende económica) que sufre nuestro país, ha obligado a llevar a cabo una reforma que aunque políticamente consensuada, ha sido contestada desde el punto de vista de los procedimientos democráticos de revisión y del contenido sustantivo que incorpora.

España no ha sido un país especialmente incumplidor del Pacto de Estabilidad y Crecimiento, aunque en el trascurso de la crisis ha tenido serios problemas para que el conjunto de la Administraciones, especialmente las territoriales, cumpliesen con los objetivos de déficit y de deuda establecidos por las instituciones y las normas comunitarias. La perspectiva de que el nuevo art. $135 \mathrm{CE}$ ayude a conseguir este objetivo, viene determinada por la imposición de unas reglas de naturaleza constitucional (con lo que ello implica para su cumplimento) y por la obligada interpretación de dichas reglas en el marco de la gobernanza económica europea, que aspira a reforzar el poder de las instituciones comunitarias y a profundizar en los mecanismos jurídicos que permitirán una mejor observancia de los objetivos plasmados en el propio Pacto.

Podría decirse, en este sentido, que el principio de estabilidad incorporado al art. $135 \mathrm{CE}$ alcanzará una mayor eficacia que en el pasado, por la razón de que el presupuesto nacional tendrá un perfil más europeo. Tanto la Directiva 2011/85/UE, recientemente aprobada, como el tratado de estabilidad coordinación y gobernanza, perfilan una transformación del instrumento presupuestario interno en un sentido temporal, al afianzarse la idea de mecanismos plurianuales convenientemente supervisados por una instancia supranacional, que exige decididamente el control financiero de todas las administraciones estatales y paraestatales. La modificación de los Reglamentos que articulan el Pacto de Estabilidad y Crecimiento, indica además que el aumento del gasto público y la deuda no podrán sobrepasar unas previsiones de crecimiento individual de cada Estado miembro, siempre analizadas y fijadas por las instituciones comunitarias. El contenido del art. $135 \mathrm{CE}$, particularmente el relativo a la consideración política de las cláusulas de escape de las exigencias numéricas del Pacto y el relacionado con el ambiguo concepto de «déficit» estructural, indica además que el poder de reforma no ha tenido en cuenta la competencia de las instituciones comunitarias en lo que respecta a la coordinación, supervisión y sanción de las prácticas nacionales que se desvíen de los parámetros del PEC y de las políticas macroeconómicas europeas.

El incremento del poder sancionador europeo, donde como hemos visto, los castigos pueden llegar a alcanzar cifras astronómicas que nuestra maltrecha economía no puede permitirse, obliga por tanto a considerar la reforma del art. $135 \mathrm{CE}$ como algo más que derecho constitucional «simbólico» realizado para calmar las apetencias de los mercados financieros. De hecho, los progresos en la centralización del gobierno económico europeo, cada vez más evidentes, y la fuerza y persistencia con la que golpea la crisis, son ele- 
mentos que hacen pensar que los cambios introducidos en la reciente reforma constitucional formarán parte del paisaje político y económico de nuestro país en los próximos años. Sin embargo, todo balance de poder hacia el ente supranacional, como el que aquí hemos descrito, requiere de una profundización democrática que se revela inaplazable tanto desde el punto de vista originario como propiamente institucional.

RESUMEN: Este artículo analiza la nueva constitución económica de la UE, a la luz de las últimas medidas adoptadas en su seno para la lucha contra la crisis económica. Además, se realizará una crítica de la reciente reforma constitucional española de 2011 a la luz de los antedichos nuevos mecanismos.

PALABRAS CLAVE: reforma constitucional, Unión Europea, crisis económica, pacto de estabilidad, constitución económica.

TITLE: Constitutional reform and the new Economic Governance of the European Union.

ABSTRACT: This article analyzes the new Economic Constitucion of the $E U$, after the new legislative measures implemented in order to deal with the current economic crisis. Besides, the author will also focus on the new Spanish constitutional reform of 2011 under the light of the new Economic Constitution of the EU.

KEYWORDS: constitutional reform, European Union, economic crisis, stability pact, economic constitution.

Recibido: 12.03 .2013

Aceptado: 02.09.2013 